H. (1 -

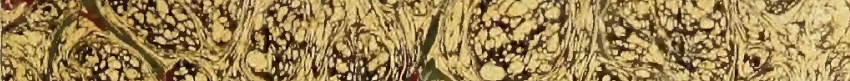

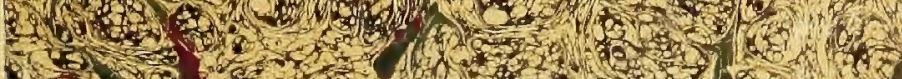

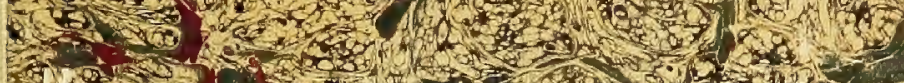
2. 45

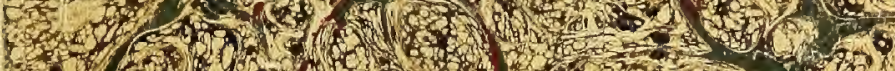

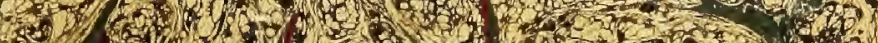

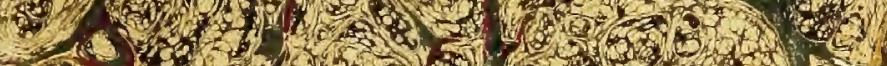

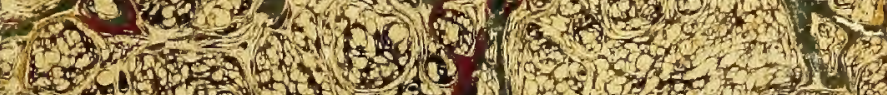
(x) a

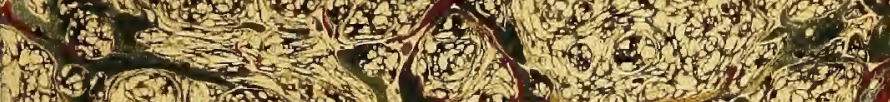
- 45 \%

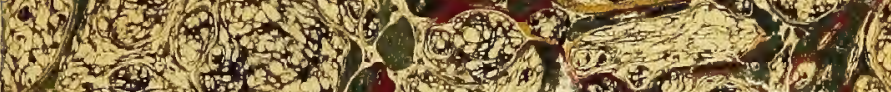
1.5.

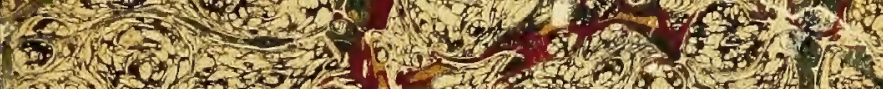
(3)

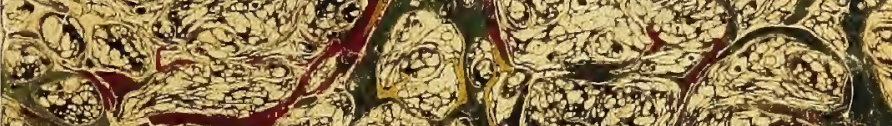
Not s

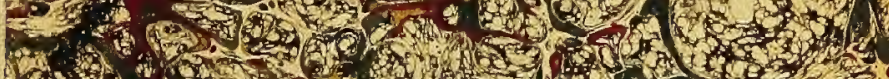
m.3. 6)

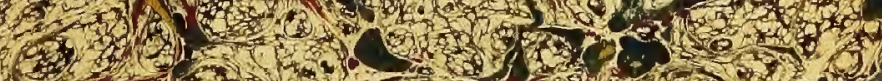

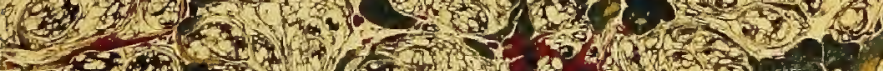
10 350

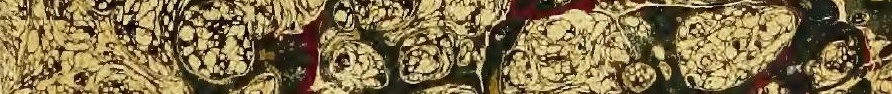

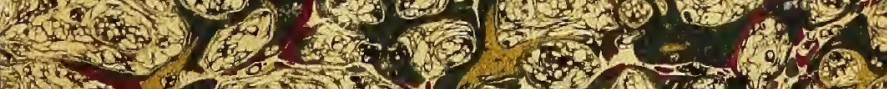
6. 2.16

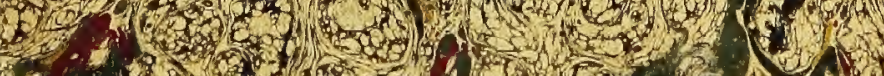
2. $x$.

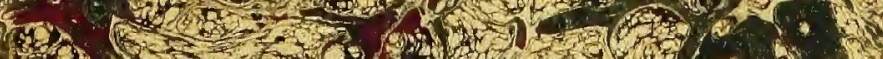
2.

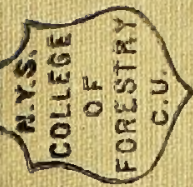

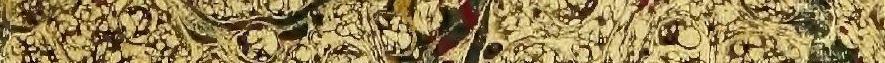
2. H. 2.

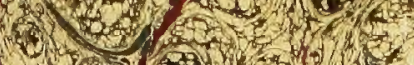




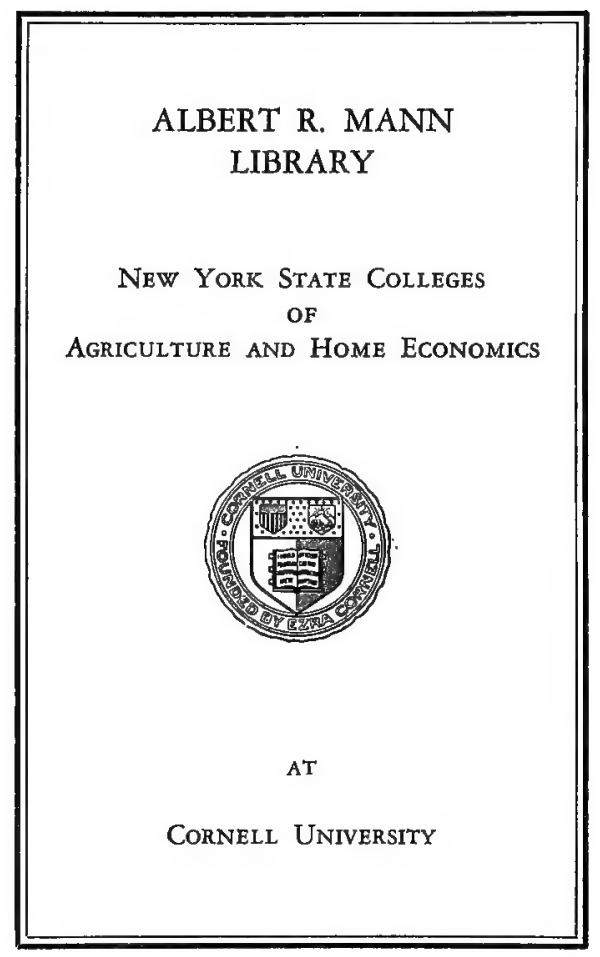




\section{QH 245.M14 Cornell University Library}

\section{Photographing flowers}

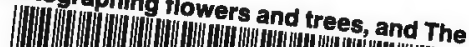

m.

31924003013913 


\section{Cornell University Library}

The original of this book is in the Cornell University Library.

There are no known copyright restrictions in the United States on the use of the text.

http://www.archive.org/details/cu31924003013913 
Photogeaphing Plowers \& Peees and Decorative Photography

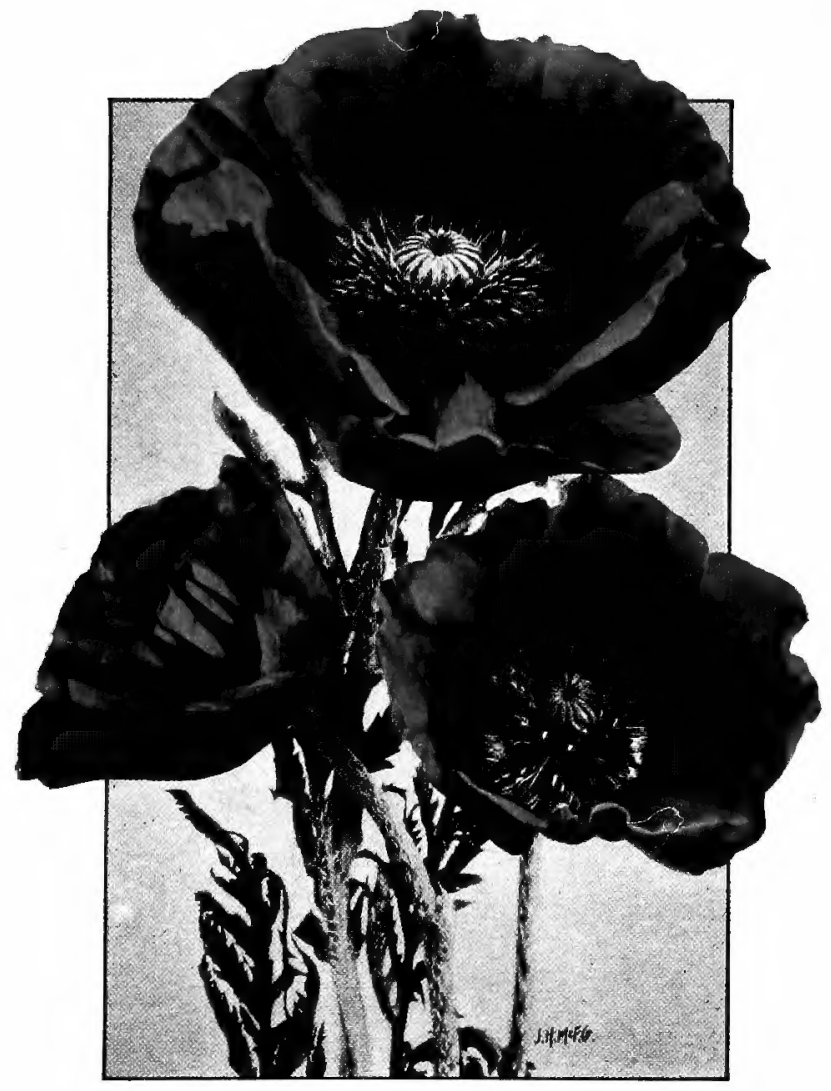

\section{Tennant and Klard Reru Yock}








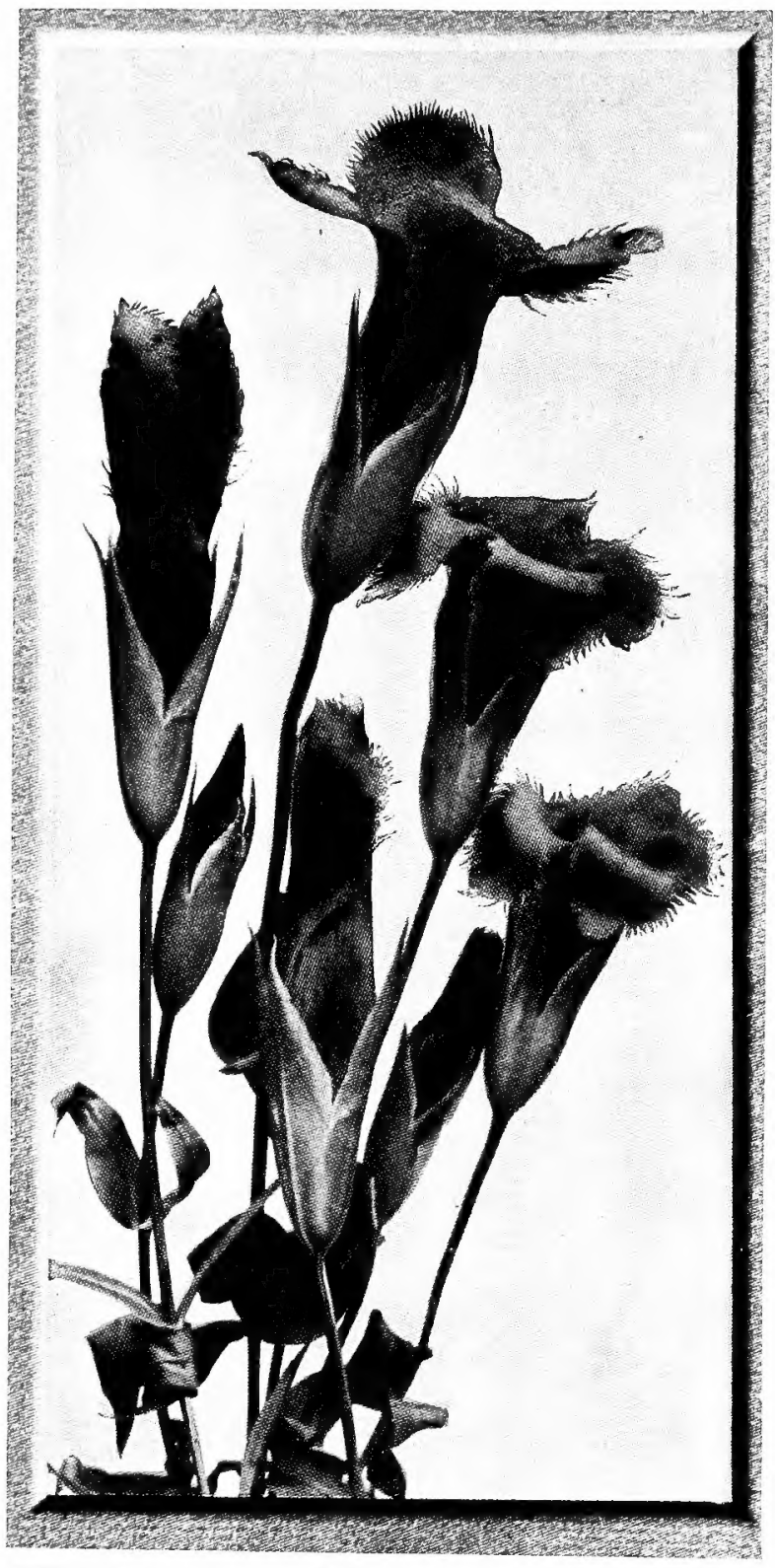

DECORATIVE EFFECT OF FRINGED GENTIAN ON PANEL J. Horace McFarland Company 


\title{
PHOTOGRAPHING FLOWERS AND TREES
} AND THE USE OF NATURAL FORMS IN

\section{DECORATIVE PHOTOGRAPHY}

\author{
$1 \quad \mathrm{BY}$ \\ J. HORACE MCFARLAND
}

aUthor of "GetTIng ACQUatnted With tHe trees," etc.

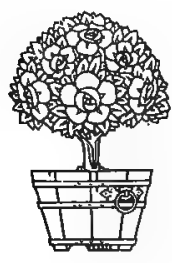

TENNANT AND WARD

NEW YORK

I9 I I 


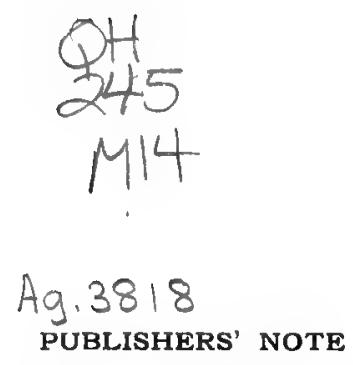

The two monographs which follow were originally published in The Photo-Miniature series, but have been out of print for some years. They are here reprinted together in response to many requests, and, as the only handbooks on their subjects at present available, will doubtless be welcomed by those who need the information they offer.

Copyright 1900, I905, I9II

By Tennan's and Ward, New York 


\section{肪hotographing Flowers and Trees}

What more interesting and fascinating branch of photography can we discuss than that which relates to the preservation, in enduring form, of a record of Nature's jewels of bloom, bud and leaf! The flowers of the field attract us, in their native environments; the gems of the greenhouse and garden also afford most beautiful and available material for photography. There is the advantage of a great diversity of form, with every possible grace in shape and habit; there is the whole gamut of color to be considered, from purest white to deepest reds, blues and purples, from delicate creamy hues to flaunting orange, with all the intermediates of azưre, pink and yellow. And the foliage also presents much of interest in the almost infinite variety of its greens, bronzes and browns.

Every resource of the advanced plate-maker in orthochromatism is needed; every trick of exposure and development may be fully employed. While the subjects are perhaps more facile than the human beings upon which ninety per cent. of all plates are exposed, they are by no means immobile or unchanging, and there is need to bring to this work all one's knowledge of light-action, all one's experience in handling shadows.

Considered as a means of artistic expression, flowers offer many advantages. The rarity of the specimens used is of no special importance, and often the commonest roadside bloom affords material for the best work.

Let me emphasize one point at the outset, even though it is a point that is of marked importance in any part.of photography. It is that to succeed in depicting by the lens and camera the forms and at least the "color values " of flowers in a manner that shall be satisfactory and expressive, the operator must love the flowers. Treat them as material only, with no more tenderness than is 
shown to the inanimate cloth used for draping a model, and you will never catch the subtleties of beauty that are reserved for those who are moved to the work by the charms of leaf, bloom and fragrance.

Not the least of the advantages of flower-photography, pursued with the aforesaid love, is the insight it gives one into the mysteries and the elegancies of Mother Nature, and the acquaintance it fosters with the plants and trees of one's immediate neighborhood. A vast enlargement of one's horizon follows a summer's work in the field and meadow, in the glen and forest, and the portraying of the beauty of the coddled pets of the florist during the winter only whets the enjoyment of the first trip into the open flower land of Spring !

But, rhapsodizing aside, let us address the details of the subject, which quite naturally divides itself into four main branches: (I) the treatment of flowers in various compositions indoors; (2) their depiction in full size from individual specimens; (3) their photography outdoors, where they grow; and (4) the photographing of trees.

\section{Flower \\ Compositions Indoors. \\ Discussing first, because it is easiest and most practiced, the photography of flowers in various compositions indoors, we inquire at the outset as to the apparatus required for the work.}

The photographing of flowers for pleasure does not require special or expensive apparatus. We may use the camera we already possess, whether it be a hand or stand camera, provided that the lens is of reasonable rapidity. The size of the picture-image, compared with the original, will depend on the focal length of the lens, which, in turn, has a definite relation to the length of the bellows extension. The bellows supplied with the average camera does not permit a picture-image more than one-fourth natural size; by means of supplementary lenses, such as the Ideal, or a Kodak Portrait Attachment a larger image may be obtained. For systematic work, however, the familiar $5 \times 7$ camera is suggested as a happy medium for all branches of flower and tree photography, and a "long focus" folding box, with bellows extension of I8 or 20 inches, will meet all requirements. It should be fitted with a reversible back, single swing (enough for any camera !), and rising and horizontally shifting front.

The lens question is one of much importance. Contrary to what seemed right, and certainly contrary to the suggestions of lens-makers of good intentions and reputations, I have found that a medium wide-angle lens is by far the most generally serviceable for all parts of 
flower photography, outdoors and indoors. The reason is largely concerned with the greater depth of focus available at a given opening, and there are other advantages which will appear as the subject develops. A Zeiss Series IV, a Morrison Wide-Angle-any good lens of not over $6 \frac{1}{2}$ or 7 inches focus for a $5 \times 7$ plate - will do good service. Of course there are special conditions which will require the use of a lens of longer focus; and if the wide-angle lens selected is either symmetrical or "convertible," one of its elements will sometimes prove very serviceable. One thing is worth attention in choosing a lens for flower photography. Get one with an iris diaphragm, in which the diaphragm opens up to the full diameter of the lens. This is of great service in focusing, enabling the correct focus to be obtained far more quickly and avoiding the eye-strain which will be felt if one has to grope around on the ground-glass for an image focused indoors at $f /$ I 2 or smaller.

Any good tripod will do, of course, but for indoor work some form of camera stand which can be readily shifted in a horizontal plane is far more serviceable than any tripod. Visions of vexation cross the writer's mind when he remembers the many times he has kicked his tripod out of a laboriously obtained position while preparing for exposure on fast wilting flowers! A regular studio camera stand is excellent for indoor work, or a stand may be improvised with boxes and a small table, the camera taking its place on top, unfastened. The special form of camera stand and exposing frame combined, described on page 'I4, is superior for this work, and the earnest operator will probably provide himself with this stand or some equivalent apparatus.

Orthochromatic plates are far better for

Plates. flower photography than plain plates, because most flowers have some shades of yellow, and all green foliage is better rendered with them. A ray-filter is not an advantage save for deep orange and for blue shades, for with the best rapid isochromatic plates, in themselves quite sensitive to yellow and slightly repellant to blue, the additional restraint of even a much diluted bichromate cell will over emphasize the yellow shades, giving even a bright canary the same density on the plate as pure white. If blue flowers are to be pictured, however, the ray-filter becomes essential. A glass cell, filled with a $\mathrm{r}$ per cent. solution of potassium bichromate, Io parts to $r$, ooo parts, will be found satisfactory. The ray-filter sent out by the Bausch \& Lomb Optical Co. is now filled with this standard solution. 
For indoor work, a rapid plate is desirable, because when the relatively faint light is considered in connection with the small stop often necessary to secure proper depth of focus, the exposure is prolonged to minutes, and a slow plate gives far too much chance fur the flowers to sink down, wilt or shake, and it also puts an unreasonable strain upon the patience of the photographer. The Standard Orthonon and the Cramer Instantaneous Iso. chromatic plates are good for this work. The Inperial Non-Filter and Hammer Ortho plates are equivalent.

The location for the indoor work is

Illumination. important. To begin with, a skylight is not required; it is even a disadvantage.

A room with two windows, either opposite or at right angles to each other, these windows provided with white shades - and opaque shades also, if it can be so arranged - is the proper thing. If one of the windows faces the north, and if the walls of the room are white or any light color, so much the better. I am fully aware that I am sadly heterodox in suggesting two sources of light, but wait; the operator will see what the use of two windows is, and it is far easier to shut off superfluous light than to struggle along with half enough. If you can't get north windows, take any other aspect. The principal thing is to have plenty of light from some direction, and to have it under control.

In addition to the room, accessories

Backgrounds. of several pieces of cardboard, the full $22 \times 28$ size, or larger if possible, will be needed, these cards to oe both white and dark. The mounting card known as "carbon black" is most excellent as a dark surface ; and a large shaded "Rembrandt" mount will also be found of much utility. The backgrounds must be free from gloss, else one has an extra trouble on hand when there are enough other items of bother! A dark gray cloth of rather smooth, even texture - as serge or flannel, or, what is even better, felt forms a very useful background; but it must be so kept as to be free from sharp folds. One of the very first things the flower operator needs to do is to photograph the various backgrounds, or pieces of them, all together, so that a comparative view of their various tone values may be had.

Several of the best workers lean strongly to either pure white or dead black backgrounds - the former obtained by white cardboard and the latter the result of the use of black velvet. While these adepts get some charming effects with the violent contrasts thus afforded, the novice 


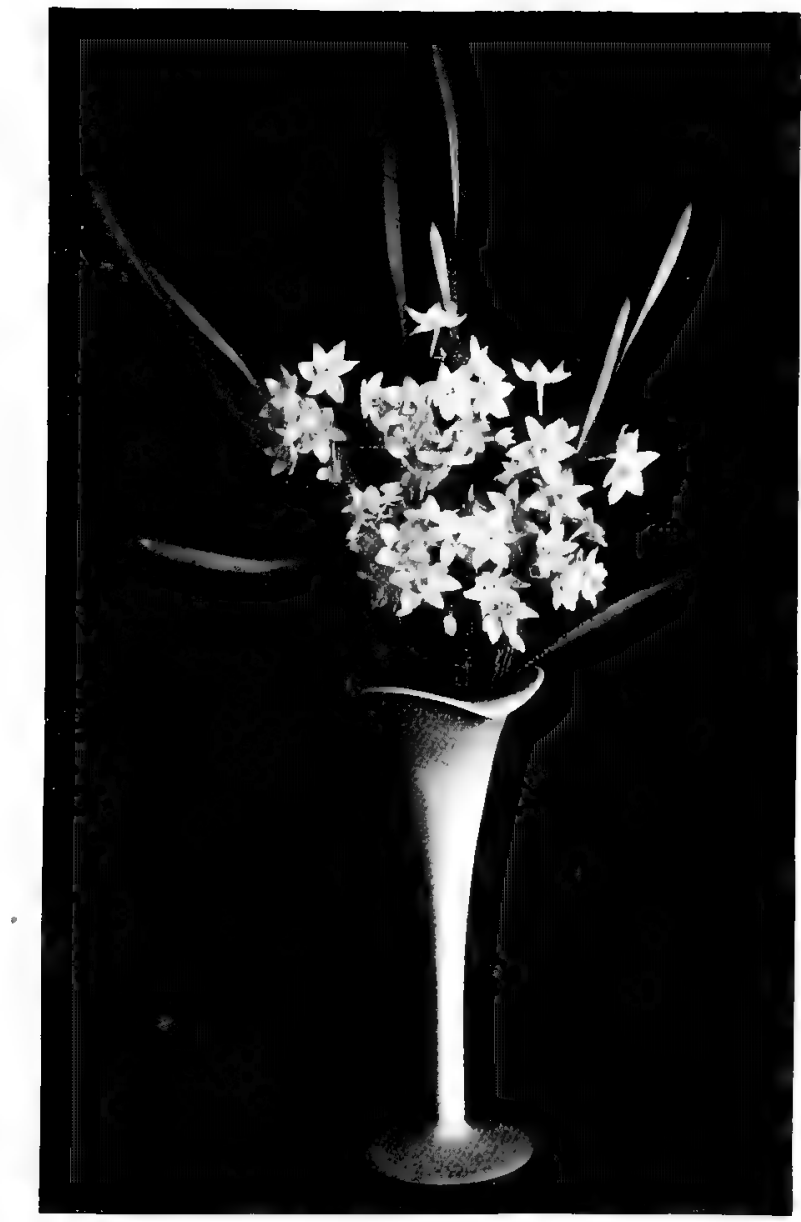

POET'S NARCISSUS

W. J. Cassard 


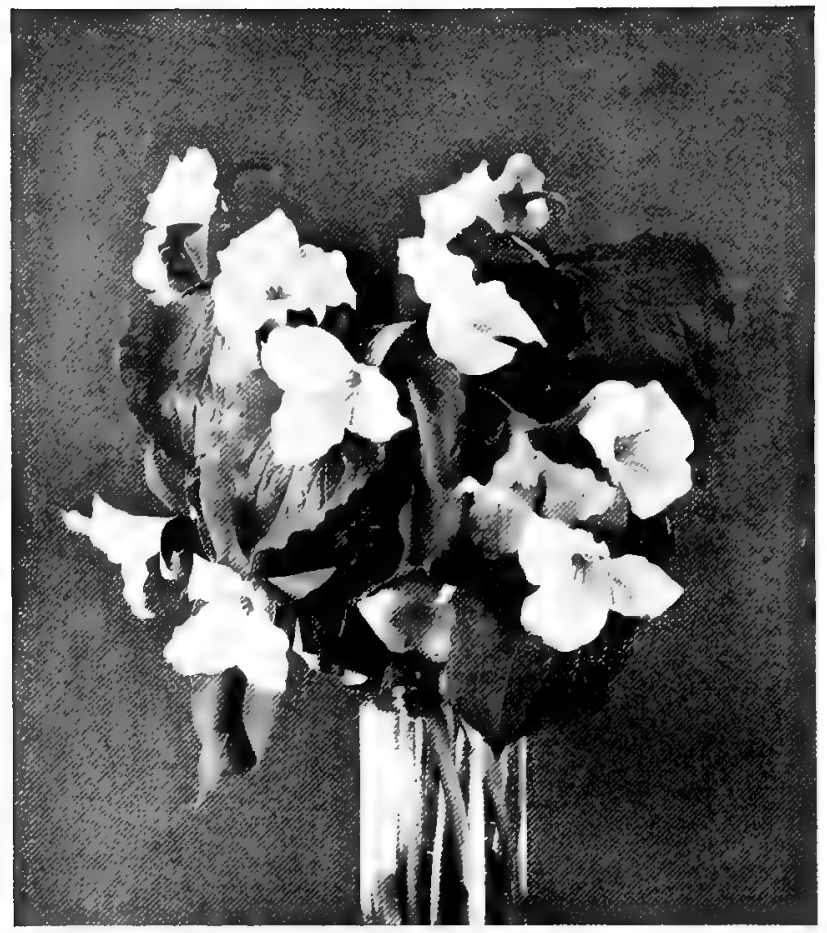

WAKE-ROBIN (Trillium grandiflorum)

J. Horace Mc Farland 
is advised to study first the neutral grounds, arising from the use of the gray cloth above suggested, and then to work also with the shaded "Rembrandt" card, before attacking the white and lack effects. The shaded or neutral grounds are rickly artistic, they are far more easily reproduced by half-tone if typographic use is ever made of the photograph, and they give a vast field for interesting graduated effects by varying the lighting.

Next to be provided for this branch of

Vases, etc. the work are vases or receptacles for the flower compositions. These are best if severely plain and simple-it is not the photography of ceramics we are undertaking, and an elaborate vase or pitcher will surely divert interest from the blossoms it is merely to hold in place. Straight, plain, clear glass vases are most excellent, especially those of few curves. There should be several vases: one with a narrow neck for single flowers, as a rose specimen; another with wide opening, for a bunch of daisies or the like. A heavy beer glass is often a joy in this use. Cut glass must be very sparingly used, or the brilliant facets will make all the picture. Plain earthenware or dark blue dull-glazed mugs afford much variety and some good effects. The exquisitely shaped and low-priced, undecorated earthen bowls obtainable at stores dealing in Japanese goods offer many possibilities in preparing flower compositions. Small pitchers are excellent for some uses ; flat dishes of oblong shape are also useful in some compositions. Of the main importance is simplicity in form and in character ; keep that in mind, and both will selection be simplified and expense be restrained.

Preparing With the camera, plates, backgrounds

the Subject. and vases ready, we may now look out for our material. We are dealing with perishable things, and they demand the most careful handling if we are to catch their evanescent charms upon the sensitive plate. To start with, let us take flowers of considerable staying qualities. Carnations may be had almost anywhere and at any time, and if they have not "stayed" too long with the florist before you get them, they will afford good practice. It may be thought an advantage if the worker is permitted to pick the flowers from the plants, taking them immediately before the camera. It is not an advantage, but the contrary. The ideal plan is to cut, not pull or break off, the flowers early in the morning, before the sun has touched them, and to put them at once into fresh water, a few degrees warmer than the dark, cool cellar or other location in which they 
should then be placed for an hour or so. So treated, they will fill up with water, and be then in fine condition to stand handling and photographing. Even the most delicate and shy wild flowers may be revived when quite wilted if treated upon this plan, remembering, too, that moving dry air will wilt them faster than anything else.

If the flowers must be transported any distance before photographing, be sure to have them wrapped in paraffine paper, or packed in a tin box so that evaporation is checked. They may wilt slightly from the confinement, but when the stems are cut off, the flowers placed in lukewarm water and then stood for an hour, or even over night, in a cool, dark place, away from moving air, they will almost surely revive, and often improve.

Let me say here that in some years of loving work with flowers, I have never observed the so-called heliotropic or sun-following movement during exposure. I have been told that my flowers would turn toward the sun, and that they would also expand during even a brief exposure; I have been gravely informed by one who posed as an authority that the only time a flower could be photographed was within fifteen minutes :ifter it had been cut, the blossom then being in a state of shock which would keep it still! But these and other theories have fallen before the common sense of practice; and the simple plans above mentioned will enable anyone who loves flowers to keep them and handle them in photographing. Keep the hands off, though, as much as possible ; the less any flower is touched, the better it will "stand up."

To return now to our carnations. Get for a start, and for comfort, several white and several of a rather cleep pink, not red; and if you can manage it, obtain some unopened buds and some of the peculiar glaucous green foliage. When they are filled up with water, as before noted, arrange them in a vase.

Arrangement: Now it does not seem particularly diffi-

Focusing. cult to arrange flowers agreeably in a Focusing, vase. Neither is it, for some people, with some flowers, for some purposes. But here we are "up against" our first technical difficulty. Get the arrangement made, put the vase with its flowers on the table or box placed to support it, put behind it the background selected, and then focus the lens upon it. It will at once be seen, if in a strong enough light, that a sharp focus cannot be obtained upon all the flowers, because, if there are a dozen carnations with long stems in the vase, they occupy a space, from back to front, of perhaps ten to fifteen inches. Of course, by stopping down the lens more 


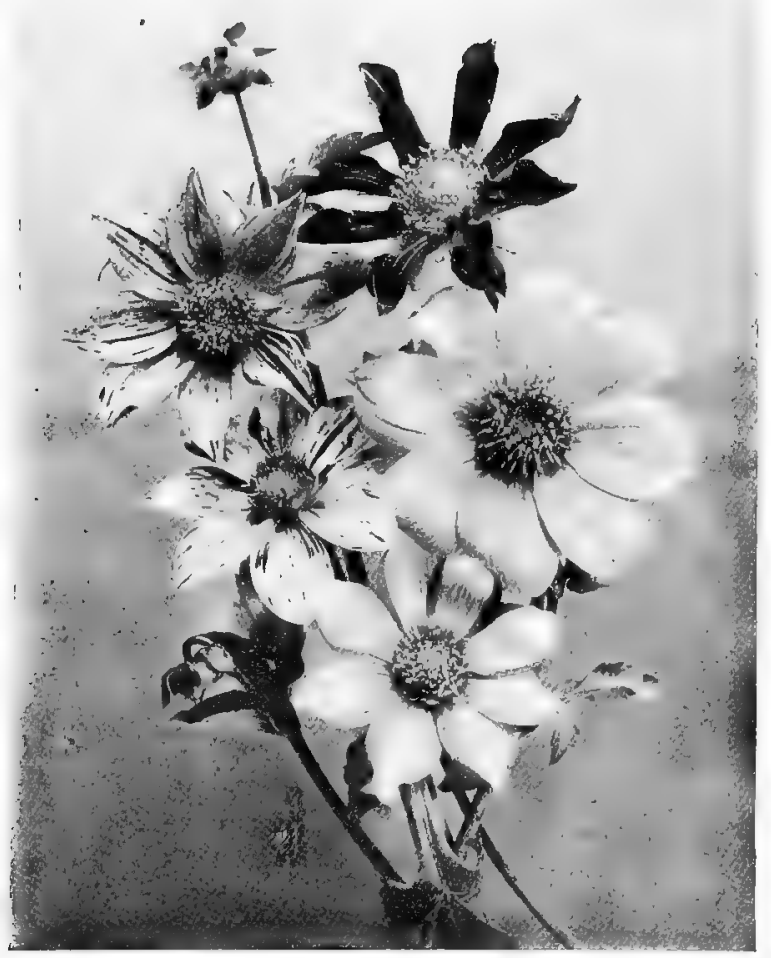

SINGLE DAHLIAS

J. Horace McFarland 


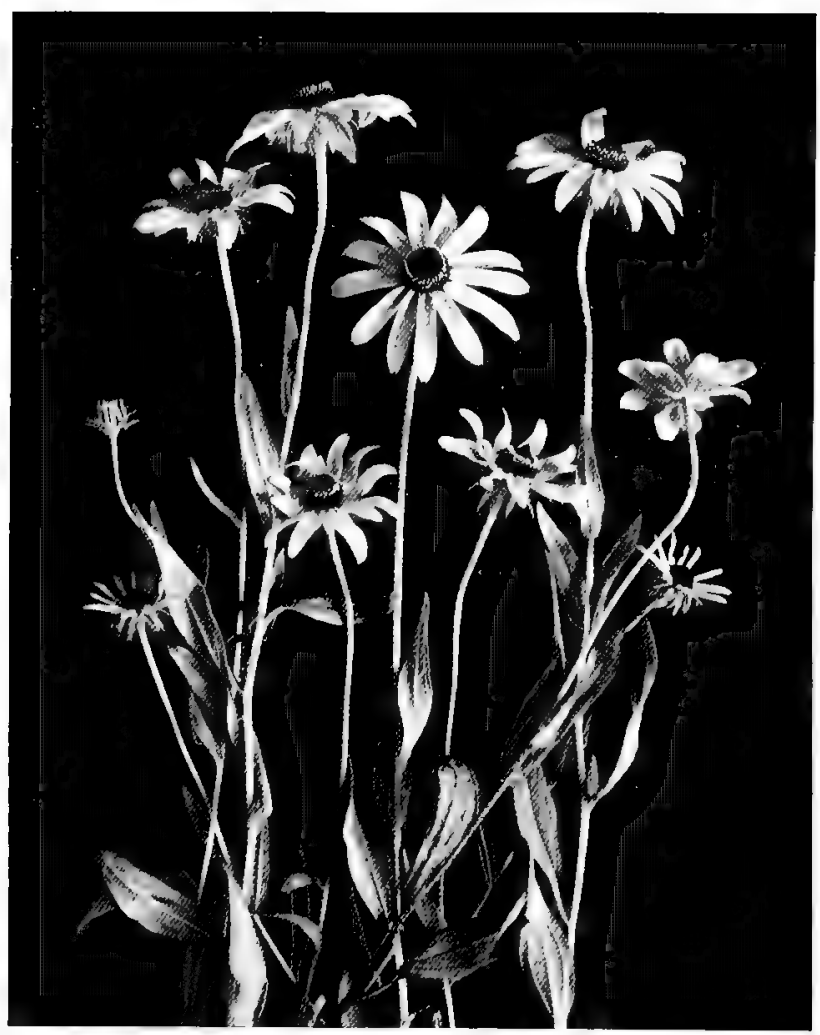

BLACK-EYED SUSAN (Rudbeckia hirla) Henry Troth 
depth of focus is noted, but probably not enough to prevent the flowers in the front or back, or both, from being most distressingly "fuzzy." It will be found that there is nothing for it but to rearrange the flowers in a plane parallel with the lens and ground glass. Probably a fine cylindrical arrangement has been made, but we need, to get sharp results, a fan-shaped arrangement. With much patience this can be made, and so made as to seem on the ground glass to be natural, and free from stiffness. The difficulty of knowing what point to focus upon with the lens "wide open" may be surmounted by selecting a point slightly in front of the center (on a plane parallel with the ground glass) and focusing sharply upon that ; for as the smaller stop increases the depth, it will be found to do so equally each way. An engraved white card with fine sharp lines, or any paper with a sharp line drawn, printed or engraved upon it, will enable the focus to be obtained very quickly, if it is placed on a flower at the selected point, and focused upon. Don't forget to remove it, however, before exposure !

Wighting fhen once arranged to your satisfac-
the Subject. faction - or as near to it as you can
attain! - the lighting becomes important. If you are working near a north window, take a position with the camera which will bring the flowers a little to one side of the direct light. Do not, for such a subject, photograph full at the carnation, in the direct line of the light; some shadows must be "hidden" in the flowers, if they are to have any form. If both white and pink flowers are in the composition, endeavor to turn the white flowers azeay from the strongest light-they are so very easily over-exposed. By half shutting the eyes, the shadows can be seen (looking at the flowers, of course, from the position of the lens), if there are any ; if not, move the whole arrangement until shadows can be noted, especially in the white flowers. Remember that the white flowers need to be lighted less than the pink, if possible; and that the foliage needs full light.

. If the work is being done by one window, by all means use a white reflector on the side opposite to the source of light, to throw soft light into the shadows. If two windows are available, the second one may be partially screened, admitting only enough light to soften the shadows. I have made hundreds of successful flower photographs in a studio where the light comes from the east and west, and sometimes great help has been had by admitting the opposite light for a fraction of the whole exposure, to round the image and soften the shadows. 
With these points decided, the focus

Exposure. obtained, the proper stop set (and it will usually be found necessary to work with a rather small opening, say $f / 30$ or $f / 42$ ), the exposure must be decided upon. Those accustomed to the use of an exposure meter will, of course, take its guidance, though the necessity for avoiding any loss of time will suggest the simplest means and the promptest action. A plan which has been found very satisfactory in practice and which has the advantage of cultivating and disciplining one's judgment, is to adopt what may be called an exposure factor, and to calculate from this what exposure to give. For instance, on this carnation subject, we may have a light which by experiment has been found sufficient to give a fully exposed portrait negative, with a fast plate and a wide-open lens, in say three seconds. Now the lens is stopped down to $f / 30$-that is I6 times the exposure; also, we have possibly cut off some of the light to gain softness, and we are working with say a Cramer Instantaneous Isochromatic plate, which is 25 per cent slower than the fastest. For the last two items we add another second to the basis, and decide the exposure as $4 \times 16=64$ seconds. Both prudence and experience dictate a little for leeway, and we give an exposure of 75 seconds, remaining absolutely still during this time, to avoid shaking the flowers.

The development, at least at first, should follow immediately, if at all possible, as in no other way can experience be obtained so quickly and cheaply. Having made a full note of all the circumstances - name of flower, lens, stop, plate, time of day, character of light (whether bright sun, hazy sun, cloudy bright or cloudy dull outside), and length of exposure, we take our holder to the dark-room, and, carefully dusting the plate, pour on it the selected developer.

For flower photographs, delicacy is more often wanted than brilliancy, and hence the developer should be one which will not give a "hard" negative. It is presumed that the worker has had some previous experience, and has control of his developer, so that he will know when to stop or when to push. We have white carnations and pink ones; we must not have both come up equally strong as to density. The foliage should not be too much accentuated; if flowers and foliage are alike, over-exposure is plainly indicated. The "Universal" developer described on page I I I find satisfactory.

The carnation composition, will doubtless keep in order for another exposure, in which the faults of the first 
negative, if any appear, may be corrected. If circumstances prevent immediate development, it will be best to make two exposures at first, giving each a different timing, and noting the result for experience. By exposing a dozen plates upon various subjects in the same place, under differing conditions as to light and time of day, we will get a fair knowledge of the time required, and accumulate also some experience in the handling of the light.

I have suggested a trial with white and pink carnations. If the negative shows a flat black shape for the white flower, the lighting has been defective, and will need to be carefully studied before using another plate. Particularly is this important in working with white and light flowers. To show white we must show shadows, and a flat front light will not do this. A good way to get information without using plates is to pass cards of both dark and light shades between the source of light and the flowers, keeping the eyes fastened, meanwhile, on the flowers and noting the play of shadows. Sometimes the excess, of light comes from above, and a portion of the window must be screened off. In a room with white walls and two windows there is usually a very strong diffused light, and to get the modeling and form of white flowers, dark shades must be used.

\section{Getting}

Experience.

Having worked out the problems of exposure and of lighting upon the much enduring carnations, other flowers may be taken, and especially other colors. I want to emphasize the fact that a dozen or so plates used upon logical and consistent experiments, even if but one good negative results, will be found to have been well used; for an ounce of practical experience is worth many pounds of haphazard attempt. Get your experience first, and get the results down on paper, noting carefully every detail of plate, lens, stop, time, exposure and development.

Shades of yello" $\mathrm{N}$ may be well experimented with next. Yellow carnations can be had, of rather a light hue, and they are mostly striped with red. Make a composition of white and yellow, and, of course, use isochromatic plates. Do not be satisfied until a negative is obtained which shows for the yellow a lower color value than a white. A bud of the Perle des Jardins rose, easily obtained from any live florist, will give a very good shade of floral yellow; or, if the experimenter is working in the growing time, common dandelions will give a deeper yellow to try upon. While getting this first experience, keep to the arrangements of flowers in vase, leaving the more artistic 


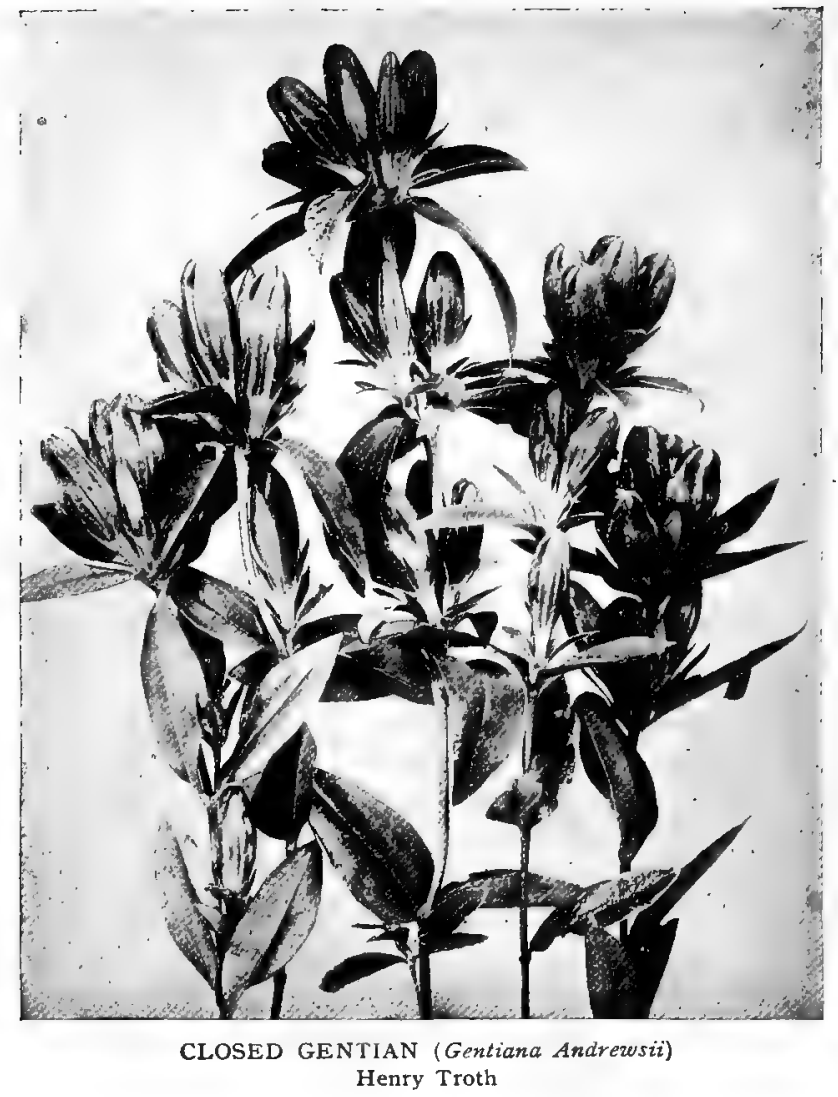


compositions for the later time when a certain basis of technique shall have been established.

It will be discovered soon that the deeper yellow shades require considerably longer exposure, and will stand a much stronger lighting. Also, it will appear that shadows are far more easily obtained, so that the character of the lighting may have to be considerably modified.

Now come to the brilliant reds of nature, which, alas, are anything but brilliant on the developed plate, even though showing so crisply upon the ground glass in vivid hues. They are the despair of the photographer, for, as is well known, red rays have but little influence upon the most sensitive photographic plate. And the brightness of scarlet, which is in such strong contrast to the green of the leaves, drops to a flat level with the tones of the same leaves when with difficulty fastened upon the photographic plate.

But we must photograph the red posies, and do the best we can. When a purely panchromatic plate is devised, the work will be easier, I hope.

Taking, then, a red carnation for experiment, and for purposes of comparison, accompanying it with a yellow one, let us make the trial. There need be now no hunt- ing for shadows - the chemistry of our work provides plenty of them - and we want the most brilliant and penetrative light we can have, short of sunlight. It must shine right into the red flowers, too; and here is a chance for a very neat bit of operating. If at all possible, get the strongest light on the red flower, a weaker light on the yellow flower, and still less on the foliage. If the latter gets the light and the exposure which are absolutely necessary for the red, it will not be of green value on the finished print, but zehite. It is best, therefore, to either light the red flowers more brilliantly by locallydirected light reflected from a small hand-mirror, or, giving the whole composition a brilliant light, to shade locally the foliage and the yellow flower. This latter, the easier plan, can be managed with a card, or palmleaf fan, or anything which will intercept and soften part of the light. To so place the red flowers in the arrangement that they get the most direct light is usually quite feasible, and this will sometimes be sufficient.

For shades of red, the exposure basis

\section{Developers} and Development. must be much longer-from three to six times that required for white and pi nk. In developing, detail in the red must be coaxed out by every art of the photographer, while at the same time, bromide will probably be needed, locally 
applied, to restrain over-exposure on the green and the yellow. It is almost useless to try to obtain satisfactory pictures of red flowers in a weak light, even with long exposures, and it is a well-known rule that length of exposure does not present an equivalent for brilliancy of light.

Combinations of red and white flowers are almost impossible, photographically, for the exposure necessary to get any sort of detail on the red will almost fatally overexpose the lighter hues. If it must be done, try to light the reds locally, as before directed, and in development work for restraint. The formula given by Cramer as "Bromo-Hydrochinon," is most excellent for this work, and, indeed, for all over-exposures.

Bromo-
I: Distilled or ice water, 25 ounces ;
Hydrochinon
sulphite of sodium (pure, crystals), 3
ounces; hydrochinon, 1/2 ounce; bromide of potassium, $1 / 4$ ounce. II : Distilled or ice water, 25 ounces; carbonate of soda (dry), 3 ounces.

For use, take equal parts of I and II. Use full strength ; and if there is any reason to suspect ten or more times a normal exposure, start with used developer, or with half the quantity of II.

For ordinary work I believe in and use the following :

Universal (Dissolve in order given.) I : Distilled

Developer. or ice water, 24 ounces; metol, r drachm; eikonogen, I drachm; hydrochinon, I drachm ; sulphite of sodium (pure, crystals), $2 \frac{1}{4}$ ounces; citric acid, I5 grains; bromide of potassium, 5 grains. Dissolve with the aid of gentle heat; leave stand a half day after solution is apparently complete, and filter into 8 -ounce bottles. II : Distilled or ice water, $12 \frac{1}{2}$ ounces ; carbonate of soda (dry), 3/4 ounce.

For use take $I \frac{1}{2}$ ounces of $I, 1 / 2$ ounce of II and 2 ounces of water, using a few drops of ro per cent bromide solution if plates do not work clear. In summer, increase quantity of water as needed; and for over-exposure, use less II and more bromide. The used developer-may wall be kept in a full bottle, tightly corked, and is excellent for starting development.

With normal exposure, and in a temperature of 70 degrees Fahr, the image should begin to appear in from 45 to 60 seconds, and development may be continued five minutes or more. Detail may be coaxed out by the use of fresh developer, diluted with four times its bulk of water. A few trials will soon" show the proper point to which to carry development. The "Bromo-Hydrochinon" may be applied for a moment to gain density, if necessary. 


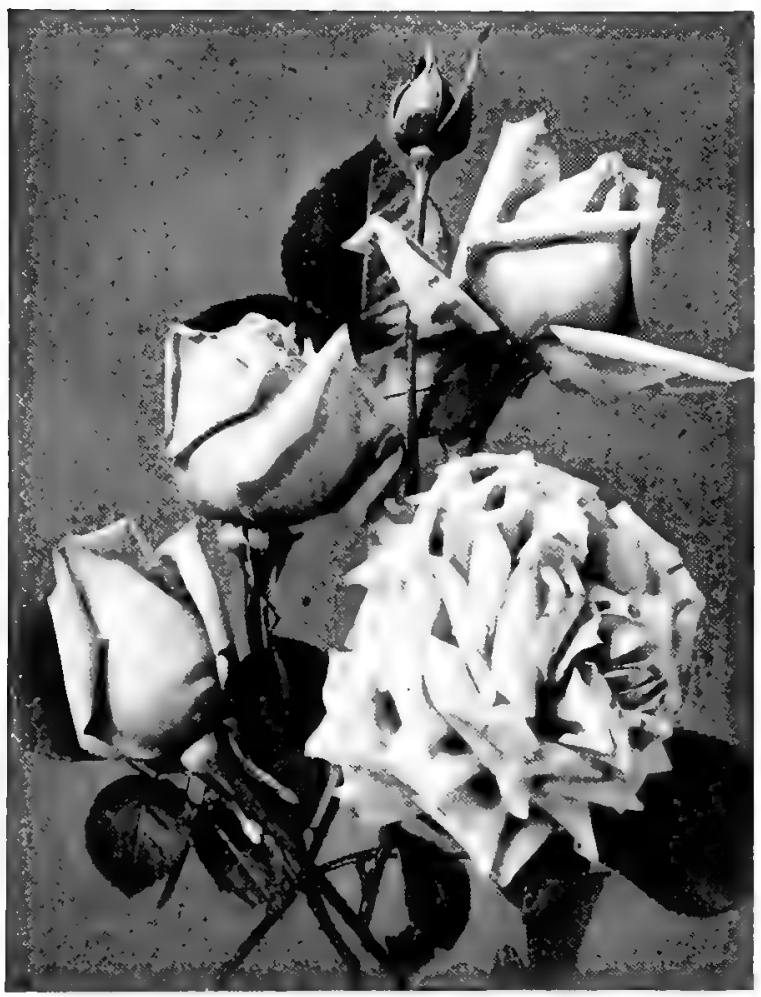

LA FRANCE ROSES

J. Horace McFarland 


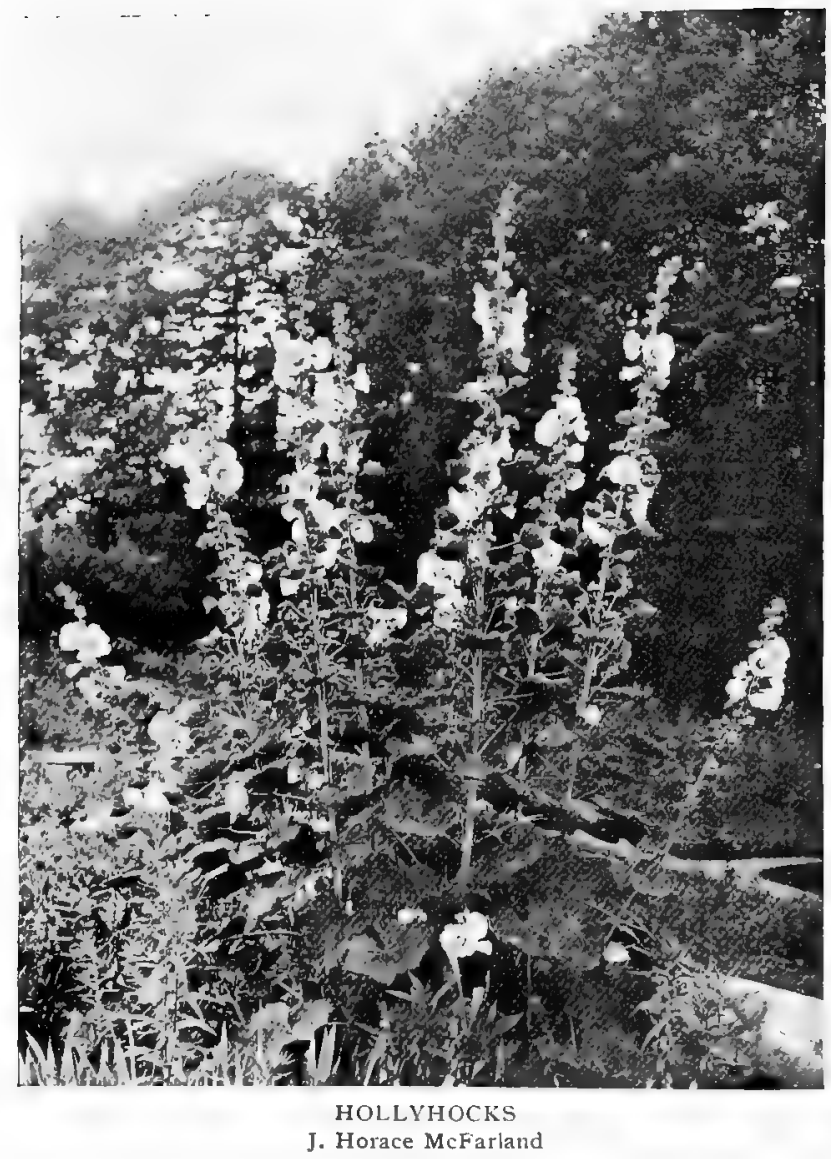


The Use of The treatment of blues must be taken a Ray-Filter. up with the ray-filter if approximately true color values are to be had. The various trade screens are available, and the special preparation of a bichromate cell has been described on page 3. This ray-filter will lengthen the exposure about two-and-a-half times. Pansies afford the most easily obtained material for experiments in working blues, and they, at the same time, give all the shades of yellow, with some odd hues which may be studied to great profit.

With some experience gained in the handling of flowers of various colors, the work of artistic composition can be profitably taken up. A bowl full of violets (and here the ray-filter is essential), a great American Beauty rose dropped on a snowy table-cover, daisies and buttercups in various arrangements-there is no limit to the beautiful pictures that can be made. The springtime will bring a host of opportunities, and the exquisite fruit-tree blossoms, the fresh opening leaves of many greens, all invite and tickle the photographic nerve. Take your camera with you, and it will show you new beauties in the great world out-of-doors, while the flower reminiscences on your plates will serve many a need, give many a.pleasant hour to your friends and yourself.

Flowers

"Life"-Size.
The second division of our subjectthe photography of flowers in "life" -size, or nearly so-presents many interesting problems, and some features of comparative novelty. One has only to call to mind the average natural size photograph as accomplished by the professional with a portrait lens, to know that such productions leave much to be desired, from every standpoint.

This work differs essentially from ordi-

Apparatus. nary view and composition photography in that some special apparatus is absolutely essential to success. A suitable lens and a camera box of sufficient bellows extension cannot be dispensed with; and success is made far more practicable and certain if a special form of camera stand is employed. When we come to work in natural-size photography, the difficulty as to obtaining sufficient depth of focus becomes acute. A handsome American Beauty rose, for instance, in its rich setting of foliage, carelessly inserted in a graceful narrow-necked vase, is a fine object, and would afford a charming photograph on an $8 \times$ ro plate-if only a reasonable sharpness could be had over a sufficient part of the surface. Try the experiment, as to arrangement, and when the composition is completed, measure 
the depth of focus which would be required to get the flower sharp, and the leaves free from excessive "fuzziness." It will be seen that a lens which would give from 6 to ro inches of acceptably sharp focus at full size is required; and this is optically, as well as practically, impossible, even with the smallest diaphragm and a consequently long exposure. Promptly the idea comes, to get the rose flat against something, and thus reduce the depth required. We proceed to put it up against a background, only to discover that the flower resents such treatment strongly, losing much of its grace. We also find, if we make an exposure, that the background is much in evidence, and that unpleasantly heavy shadows obtrude themselves. It is also noted in following the suggestions given in previous pages as to lighting, that it is hard to manage so as to avoid flatness.

If we could lay the rose down and look at it with the camera in a vertical or nearly vertical position, several of the first-named difficulties would disappear; and if we could secure the flower practically floating in the air, so that the hard background shadows were eliminated, the balance of the troubles would be at an end. Just this can be accomplished with a form of vertical camera stand, to which is attached a plate-glass exposing surface or platform; and the vertical apparatus, if made easily portable, will also help greatly in giving perfect control of the lighting. Several such forms of apparatus are hereafter described and illustrated.

For consistency's sake, we may well begin to consider our apparàtus by taking up the lens question. For natural-size work a wide-angle lens is a necessity, not a mere convenience. A study of lenses, in connection with No. 79 of The Photo-Miniature, will explain why, wherefore we do not discuss the optics of it. . A larger-sized camera than $5 \times 7$ will be found very desirable also, because of the obvious limitations when one takes up large flowers. The whole-plate size, $61 / 2 \times 81 / 2$, is my favorite for this work, and a lens of good quality which does not exceed $71 / 2$ inches focal length is about right to use with it. With such a lens, and a bellows which will extend to 18 or 20 inches, at least, we are well equipped.

The camera box should have a rising and shifting front, and a single swing. It will be found to be a great advantage if the rising front is operated by a tension screw so that it may be held exactly where it is wanted, rather than controlled by a stud working in a ratchet, whereby the movement is in certain arbitrary distances. When flowers are once arranged before the lens, we want every facility 
for locating the view on the plate without disturbing the fragile subjects themselves.

Vertical

Now as to the appliances for looking Stands, Etc. downward with the camera. There are several such devices, and nearly every worker of much experience has some sort of a plan or machine, more or less useful and practicable. By far the best is the form illustrated in Fig. $\mathrm{I}$. This is a studio

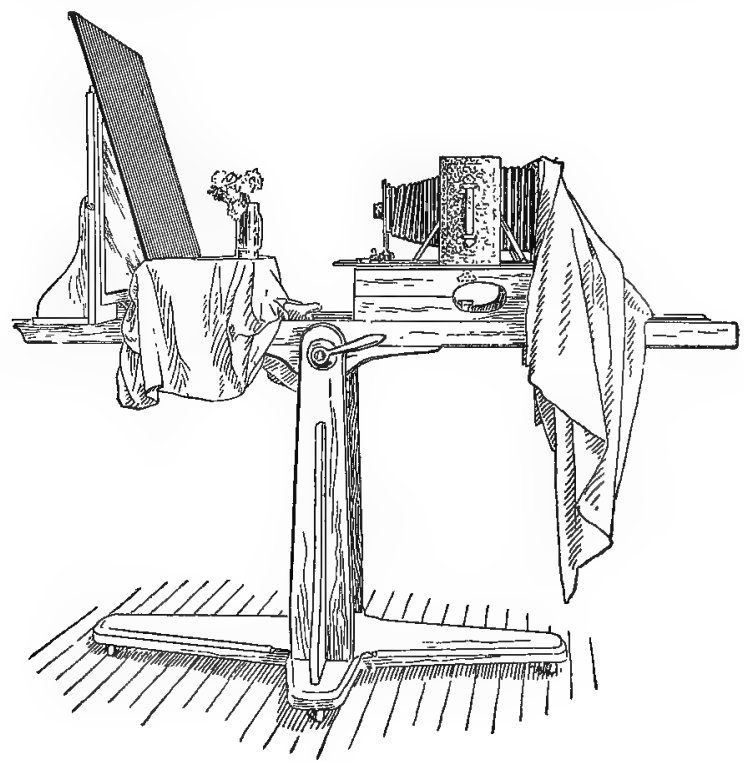

Fig. I.

camera stand, suited for many uses. It is perfectly adapted for horizontal, as well as vertical work, and by the addition of a couple of supporting sticks and a cloth to shut out superfluous light, together with a turn-table device for holding negatives, it becomes a most excellent lantern-slide and transparency apparatus. This is mentioned because many who would hardly feel like having such a stand made for flower photography alone will find it entirely practicable in its combined usefulness. Indeed, no one with much studio work, such as the 
photographing of various objects of small size, copying in any size, enlarging, lantern-slide and transparency making, can well dispense with an equivalent apparatus. Its perfect flexibility permits so ready a use of any light, and such thorough control of the light, that I am sure any worker who once sets up such a stand will always regret to have ever to handle a tripod indoors again.

Two views of the stand are shown. The first, a side view, gives the appearance of the device with the track for the camera stand in a horizontal position, as when working on flowers which cannot be laid down, or on compositions in reduced size. The frame carrying the plate-glass then becomes a support for the background selected, and the article to be photographed is placed on a box in front of the background. The plate-glass frame is movable along the track, and the sliding stand for the camera, in the center of which is a slot through which comes the tripod-screw to hold firm the camera, is controlled partly by a strong brass window spring, which tends always to pull it away from the plate-glass end. This stand, or box, is fastened by a large thumbscrew, easily accessible through the opening in the side of the box.

The method of control of the track, carrying both camera and exposing platform, is easily seen. This track is cramped between the two uprights, and the hand-lever at the side, working a nut on a screw-thread, serves to hold it firmly in any position.

Fig. 2, more important for the present discussion, shows the apparatus in position for flower photography. The plate-glass is nearly vertical, as will be noted - it can easily be made entirely so - and the relative distances are well shown, as the drawing was made over a photograph of the stand in a much-used studio. Note that keeping the plate-glass exposing platform some six inches away from the floor gives opportunity to slip in any background, out of focus, and thus unobtrusive. See, also, that while as here shown, the apparatus is arranged for making natural-size work, there is plenty of room for the camera box to be drawn back, so that objects on the glass can be photographed at a considerable reduction. Also, see that by bringing the camera still closer to the object, enlargement may be accomplished up to the limit of the bellows capacity of the camera.

The whole apparatus, which stands on a crossed frame, is mounted on smoothly-running casters, and it may thus be readily wheeled about without disturbing the camer 


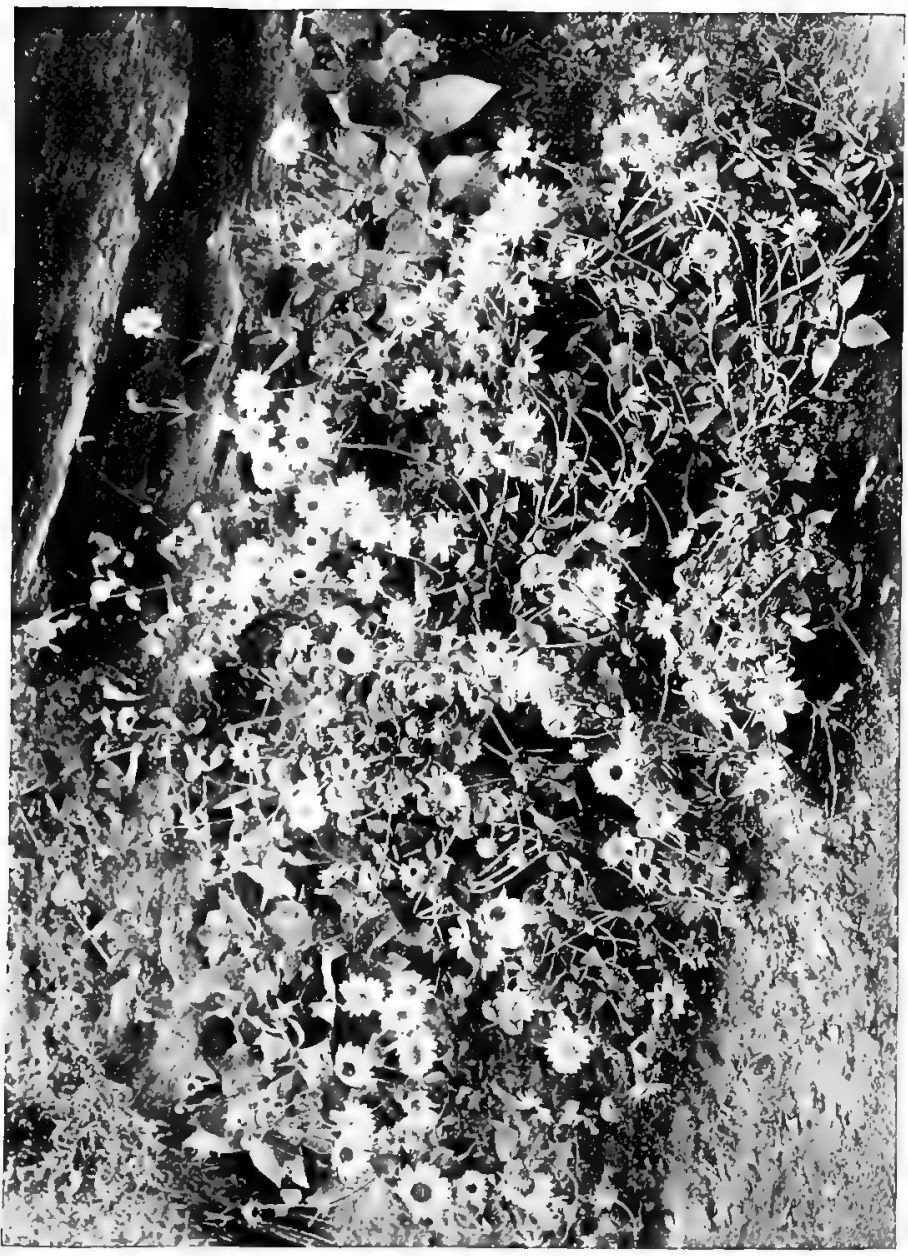

恋 
or the objects being photographed. This gives a chance to make the lighting whatever one desires, and it will

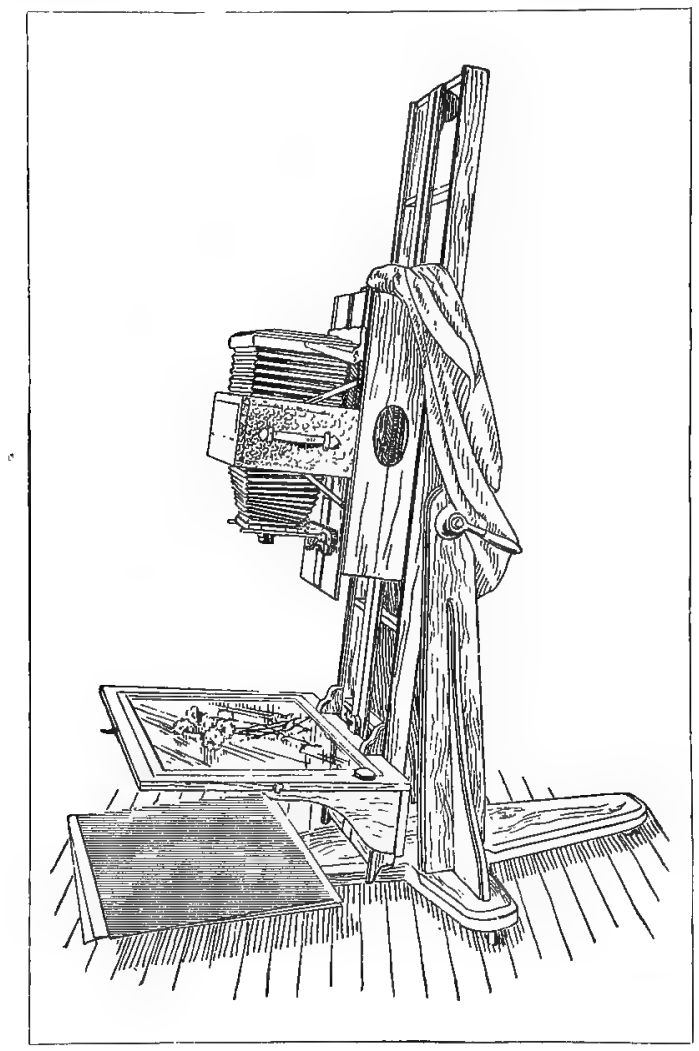

Fig. 2.

soon be discovered, not only that top light is much quicker than the often much-reflected side light, but that it is far more easily controlled, in every way, giving also many desirable effects. 
There is just one troublesome feature

Reflections. which presents itself in connection with a downward position of the camera, and that is the matter of reflections from two sources-the ceiling of the room, if it is light in color and strongly lighted; and from the polished front and lens of the camera itself.' A sky-light, of course, is worse yet, as I discovered to my sorrow after working one long day in a greenhouse, with no chance to develop trial exposures. I had numberless pictures of the sky-light windows in great and unwelcome detail! The only sure way to obviate these reflections always - and sometimes I have worked for months without once being bothered!-is to have a wire frame made to fit on the three sides of the front of the camera, flaring outward, and lined with black velvet. This cuts off all the side-light from the lens, and if it is made large enough, also shuts off the possibility of any reflection from the ceiling of the room. A diagram

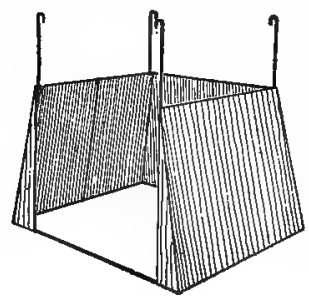

Fig. 3 . (Fig. 3) shows the idea. It is made so as to hook easily over the edges of the camera box, and one part is hinged, so that access may be readily had to the lens. This device may fold on itself, taking little space while not in use. A black cloth or a dark card, with a close opening for the lens only, may sometimes be satisfactory for the cutting off of reflections.

The above described camerastand, which is a composite of the devices of a half-dozen experienced workers, may be well made by a good cabinet-maker for from $\$ 25$ to $\$ 35$, and all complete with the lantern-slide frame and turntable, and the ground-glass attachment, which is a necessity for that use, for about $\$ 8$ more. A much cheaper and more simple frame, not so convenient, of course, is represented in Fig. 4. In either of these devices, the object is attained of securing a transparent support for the flowers, and thus disposing of the heavy shadows and objectionable background texture.

One more almost indispensable, but

A Focusing Device. fortunately very simple, appliance may be quickly described. It is a focusing device, and is shown in Fig. 5. A piece of wood an inch thick is notched out into half-inch steps of a half-inch rise, and on these steps are pasted large figures (from a calendar, for instance), giving the inches, whilẹ a cross-line îs 
drawn with India ink and a fine-pointed pen somewhere on each step. The use of this little thing will shortly appear, and it will save much time in obtaining a correct focus.

With the apparatus ready, and a location similar to that described in the first section of this treatise, we may begin, and for our first experiment let us choose again the long-suffering carnation, not only because it will stand handling, but also because it does not heap up difficulty by requiring great depth of focus.

Temperature, A parenthetical note is in order as to Etc. tions, full of vigor and water, simply melt before the camera when used in a hot, dry room, the air in which was loaded with chemical fumes. $\mathrm{Mr}$. Kurtz's magnificent studio, in New York, fitted for three-color photography at a great cost, was useless for photographing flowers, in themselves the best possible subjects for his process, because the good man could not be made to see that in an atmosphere of collodion and cyanide fumes, at a temperature of $95^{\circ}$ to rro ${ }^{\circ}$, no self-respecting fiower could be made to stand up five minutes. Therefore, keep the work-room as cool as possible, and have the air moist. If a bare floor is present, sprinkle it with cool water; if a carpet prevents this, dampen the air with an atomizer. This is being good to the flowers, and

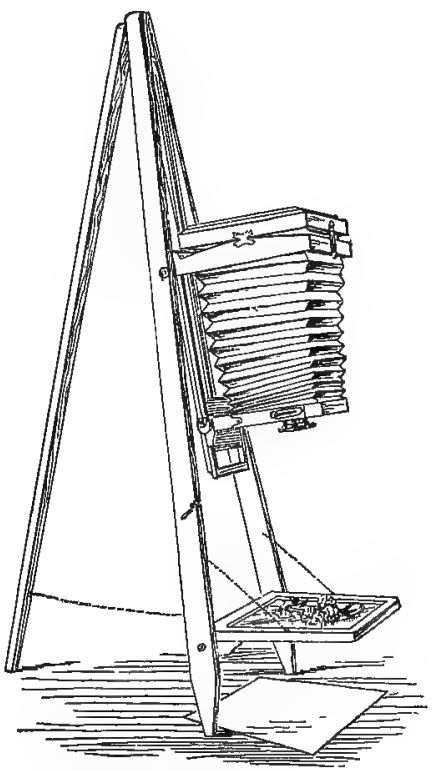

Fig. 4 . quite as important, it is restraining the dust particles in the air, which are apparently very anxious to be photographed full size. Lastly, keep the flowers in water until 


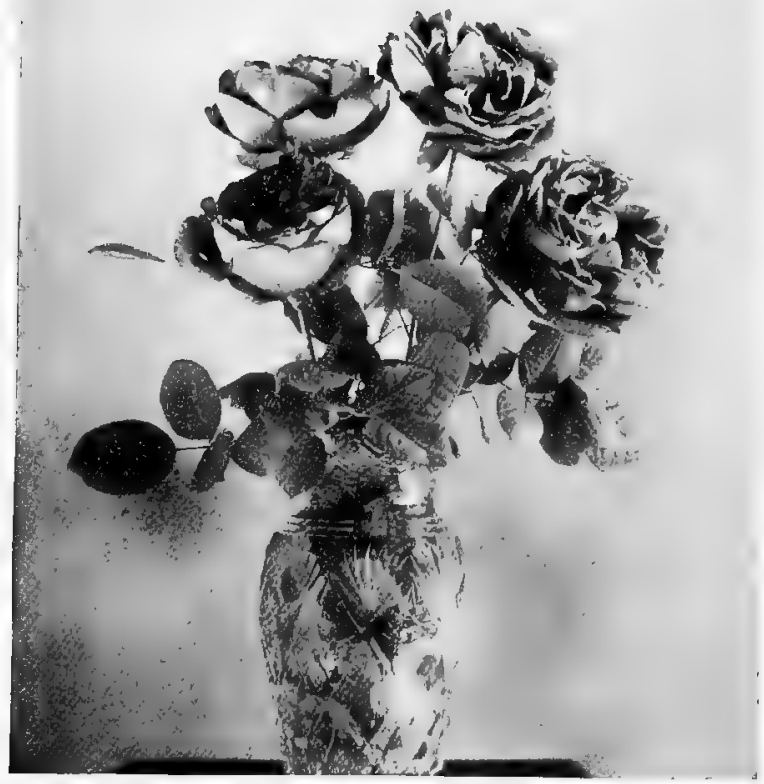

AMERICAN BEAUTIES

W. J. Cassard 


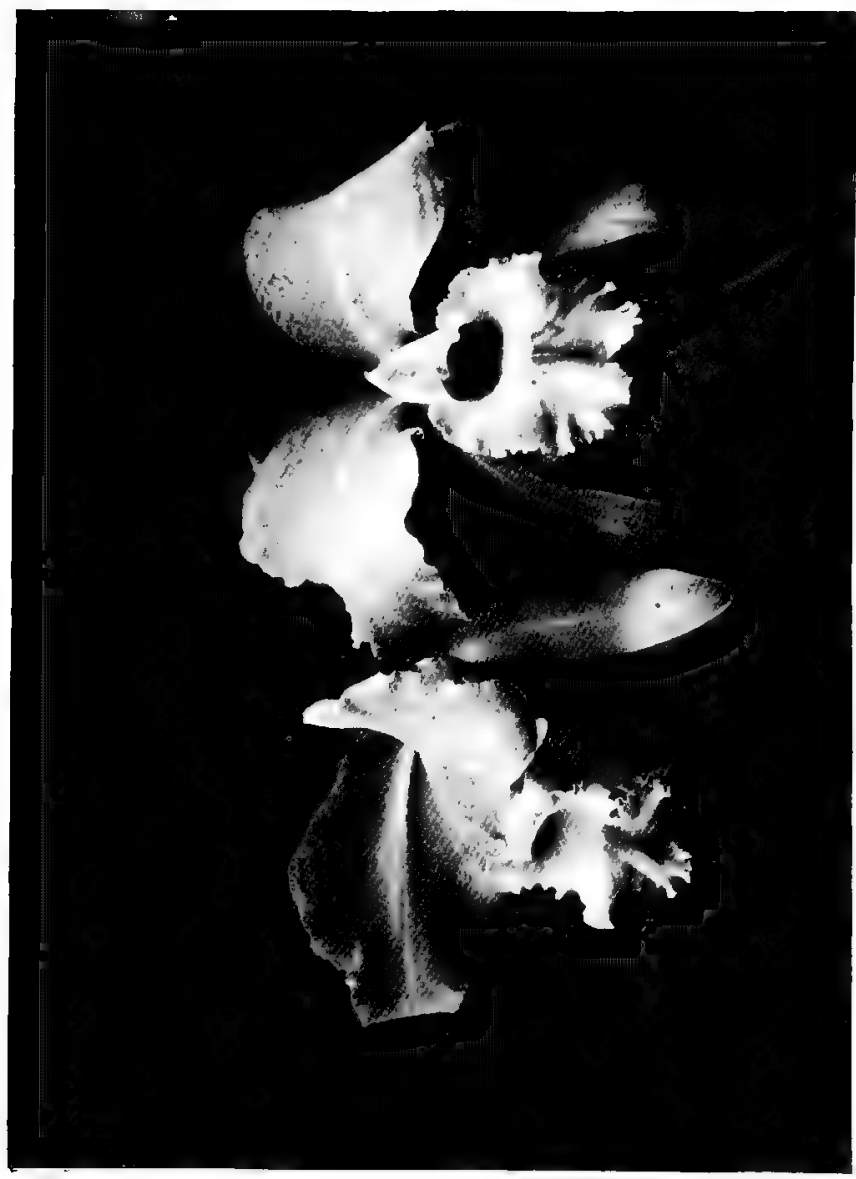

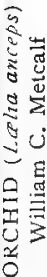


they are actually to be worked, and as they are taken out, dry off the water with soft tissue paper, or a rag which will not "lint." Drops of water on flowers, stems or leaves must be absorbed before an exposure is made.

Other

Make \& composition on the plate-glass

Preliminaries, with the carnations (first having carefully cleaned the glass on both sides, so that no specks, spots or dust atoms show), arranging them as you think best, defeating their natural stiffness if possible. The buds, if any are at hand, will help; and to get a look into one flower, it may be necessary to crack its stem just below the flower, propping it up from below, out of sight of the lens, with a little bit of wood or rubber. Before going too far with the work, look at it on the camera's. ground-glass, so that the right position on the plate is assured; it is not easy to move successfully a finished composition.

Also, get the focus before finishing the composition. To work full size, the lens must be equidistant between

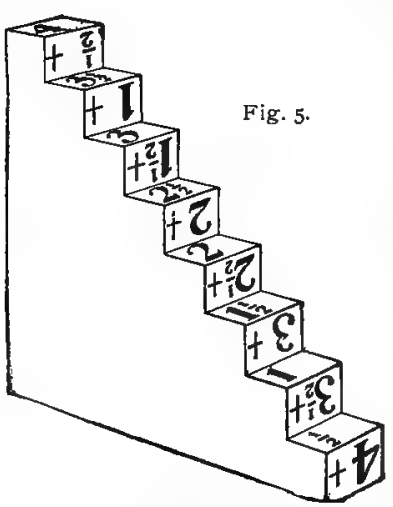
object and ground-glass. If a 7 -inch lens is in use, the distance from the flowers to the lens must be I4 inches, and the camera will need to be pulled out to that distance also. Here comes in the great utility of the little focusing device illustrated in Fig. 5. Instead of worrying long in an attempt to find the proper spot upon which to focus, slip the device into the composition in such a way that the light will fall strongly upon the steps. Note how many inches high the flowers are, from the glass to the extreme point. It may be three inches. Now, as we want the sharpest focus in front always, and as the focus deepens equally from a central point when the lens is stopped down, focus upon the 2 -inch step, getting that perfectly sharp, without paying any attention to the flowers. In my own practice I usually sharpen upon two numbers equally, and this diffuses the focus somewhat better. In this case, it would be upon the $I 1 / 2$ - and 2 -inch steps. It will be found probably much easier after obtaining nearly the size and focus by the camera front, to get 
the final sharpness by moving either the back or the whole camera up and down. The heavy spring upon the sliding camera stand helps in this work, taking up much of the weight. The ideal arrangement would be a rack and pinion upon the camera stand for focusing, and I hope prosperity's smile will eventually encourage me in obtaining such a time- and strength-saving adjunct.

Sizes may be more readily ascertained, and exact locations upon the ground-glass obtained, if it is carefully marked off into inch squares, ruled with India ink on the ground side. Diagonal lines, crossing the exact center, will also be obviously useful.

The location obtained, and the composition made, we must consider the background. Try for this first exposure a neutral ground, afforded by a dark gray cardboard, slipped under the plate-glass frame, which, as noted, is some five or six inches from the floor. The character of the background may be greatly modified by its lighting, as a little experience will show. Often it may be tipped up at one end, to advantage, and sometimes I have secured a fine atmospheric effect by fixing the card into a semi-cylindrical position, excluding light from two sides under the plate-glass. Experiments with various backgrounds will soon provide the operator with much valuable data, and teach him certain means of obtaining certain ends. As before mentioned, a graduated background, such as may be made by means of an air-brush on any card-mount of suitable size, will give many charming effects. Large sheets of printers' cover papers, of antique finish and dark shades, are admirable backgrounds. Princess, Belgrade, Oriental, Manhattan, Imperial and Herculean are trade names of some suitable papers, and there are many rich shades of each. Any paper warehouse or artists' supply store carries these papers.

Now comes the question of lighting.

Lighting If our carnations are white, or pink, or yellow, or a combination, we need a rather uniform light, striking first the tops of the flowers, and all that has been said about the absolute necessity of "hiding shadows". in the flowers comes most strongly into force. By moving the stand, and watching the play of light and shadow; by manipulating the curtains to either or both of the windows; by holding up various cards as reflectors or shades, we get many different lightings. Be careful that the center of the composition does not miss the light that the sides are absorbing, and develop into a nasty under-exposure. Try also to have a sufficient light on the stems and foliage, without admit- 
ting or reflecting so much light on the shadow side as to flatten the whole composition. It will soon be found that troublesome interior shadows may be illuminated softly by light reflected into them by a white cardboard, and the great advantage of a double source of light (such as is afforded by windows opposite or at right angles to each other) will appear. As before noted, a brief flash of brighter light into the shadows during a small part of the total exposure will often give beautifully clear but not hard detail in the darker parts.

The time of exposure can only be

Exposure. learned by experience and the using of plates. The larger size means longer exposure, of course; but how much longer depends so entirely on purely local and incidental conditions that it cannot be more than hinted at. I do not use an exposure meter, but work with an exposure factor (see page 8), and if one has done his fair share toward the prosperity of the amiable dry-plate manufacturers, with a due exercise of the bump of remembrance, he should be ready with a factor for nearly every kind of weather and time of day. Beware of the deceptive light of early morning and the yet more deceptive yellow radiance of the waning day. Both times need far longer exposure than at first seems requisite, and the evening light, while beautifully soft and often strongly orthochromatic, needs much time to act. Also, note the tremendous activity of the chemical rays from Io A. M. to 2 P. M. of summer days, especially if hazy clouds diffuse the light.

Try two or three plates, at different exposures, on the same subject, and thus obtain some needed experience at the start. Our carnation subject will await us while we take the holder into the dark-room and perform that evermysterious incantation called development, which shall bring out faithfully upon the creamy white surface of the plate all the lines and shades of the flowers, if our exposure has been "normal." And here let me say a word or two about development. "Normal" exposures are, of course, always vastly preferred; but alas, how few they are! The portrait photographer, working days and weeks and months in the same studio and with the same plates and the same light, upon the same human "mugs," gets to be an automatic machine as to exposure, and he has normal exposures all the time. But the amateur: working once in a while, and with ever-varying materials. and conditions, cannot have the machine-like regularity of his professional brother, and must therefore use the great resources of skilful development to make up for 


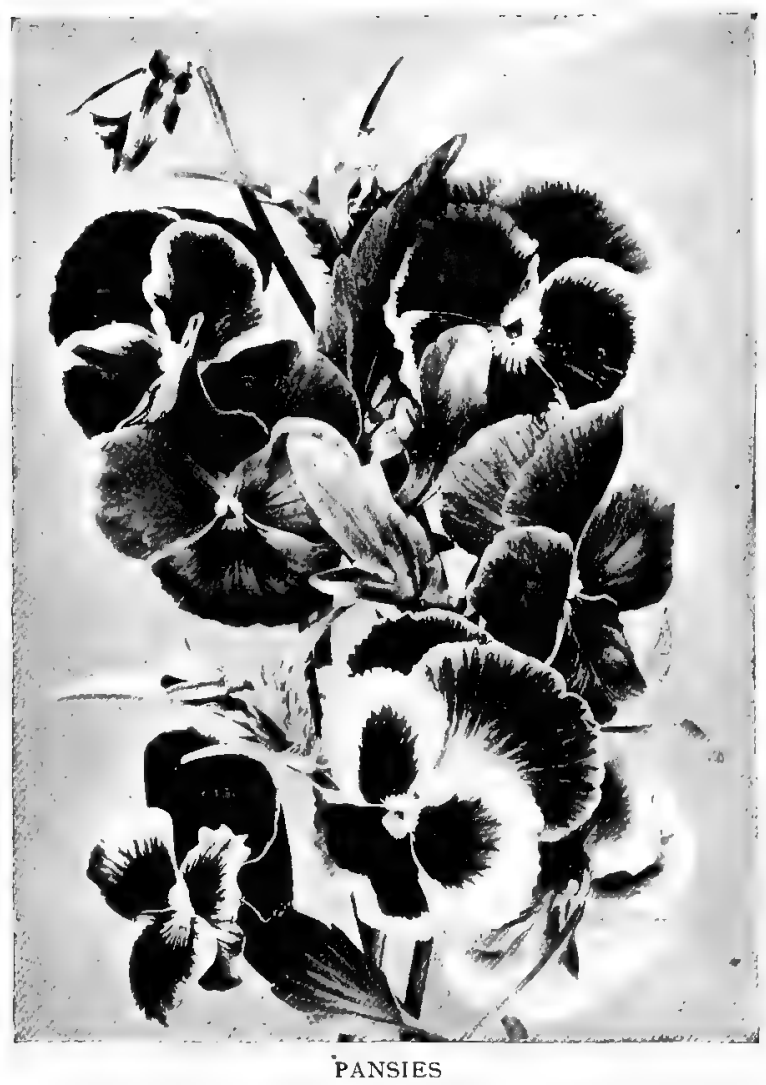

J. Horace McFarland 
mistakes in exposure. The portrait artist may, and often does, send for his sitter again ; but those of us who chase the gems of the field know that our subjects, many of them, can be sought for, with much effort, but once a year. Their delicate texture is all too frail for the camera's burning glance, and the basilisk eye of the lens may rest upon them but once only. Thus we see the importance of getting experience with the hardier sisters of the greenhouse fraternity, so that our attempts with the rare and delicate treasures of the field and meadow may be successful at the first chance they afford us.

Now while development affords re-

Development. sources for over-exposure, it will not bring out what has not been put upon the plate by light action. Under-exposure is failure, notwithstanding the freak developers which periodically claim to give a good image at "one-third the exposure of any other." Therefore, avoid under-exposure! When I look over my negatives, and see-alas, too often! - the " might-have-been" members of the family, those which needed only another fraction of time, I am moved again to exclaim, "Under-exposure means the ash-pile!"-or some other abode of departed possibilities.

But to details. We have exposed according to the best information, and we think we are right. It is the height of recklessness to pour on the active, fresh, normal developer upon the uncertainties of our exposure. No; let us feel our way. Slip the plate into the tray in almost entire darkness, and cover it with a card or another tray while a "tentative" developer is prepared. If we work one of the benzene ring of reducers - hydrochinon, eikonogen, metol, tolidol, or the like - and have kept a little of it that has been used before, that is good to try our exposures. If the image comes up quickly - within I5 to 30 seconds, in a temperature of $70^{\circ} \mathrm{F}$. - we have over-exposure to deal with : the weak developer must be poured off, the plate quickly rinsed in cold water, and the developer for over-exposure applied. In general, it is the first 60 seconds that decide the ultimate fate of a negative, for if a normal developer be allowed to act that long on an over-exposed plate, flatness is sure to follow.

As this is not a treatise on development, that subject will not be pursued, more than to say that it is important to avoid hardness in flower negatives. We will have constantly to deal with extremes of contrast in white flowers and dark green leaves, and the deposit must not be of the "soot and whitewash" character. Therefore, a developer is indicated which will not give the greatest 
density. (Metol-hydrochinon is a favorite combination; also, see formula on p. 20.)

More

'I'o return to our poor carnation How-

Experience. ers, all this time wilting before the lens while we are experimenting and philosophizing ! We may, if we find the first exposure too long or too short, try another, and then pass to other flowers and other compositions. The remarks previously made about red and yellow flowers, and concerning ray filters, apply here with double force.

The most difficult flowers, often, are large white blossoms, with deep green foliage. A great white rose, as The Bride, or Captain Christy, presents an extreme of contrast which will tax all our skill, alike in composition, lighting and development. The beautiful native "wakerobin," more generally known as Trillium grandiflorum, is another subject of much elegance and equivalent difficulty, because of its contrasts of white, blush-pink and deepest green. A gorgeous blue and white pansy, with a yellow eye, or a cluster of the delicate wistaria, or the lovely "bluet" (Mertensia Virginica), or the stately purple and gold iris, will test the control of contrast and the resources of orthochromatism.

In general, it will be found that great contrast in the subject must be met with soft and fully diffused light, especially in dealing with white flowers and glossy leaves, which latter are simply unmanageable in a brilliant light. The beautiful kalmia, or mountain laurel, is a case in point; its deep, shiny leaves, together with its exquisite cup-shaped white flowers (in which shadows refuse to hide) and its delicate fluted pink buds, are my despair! I hope some one who reads may have the joy of a full triumph over the photographic difficulty of this glory of our Allegheny mountain-sides.

Where red is to be photographed, a brilliant light is essential. The bright Crimson Rambler rose, for instance, must have the light, sharp light, poured into it ; and still more will its greater sister, the queenly Jack, and other crimson full-bosomed flowers, need brilliancy of direct light. Give such flowers three or four times the exposure deemed necessary for lighter subjects, shade the foliage as much as possible, and develop with a strongly restrained reducer. The "Bromo-hydrochinon" formula, already given, is advised as peculiarly adapted for this work; it affords density without undue hardness.

Flowers

Notwithstanding the great value of the

Pendent. apparatus for downward exposure, it must not be used for all subjects." Some 
of the most beautiful flowers are in pendent clusters or racemes, and cannot be laid down without losing all form and grace. The fragrant blossom of our common wild locust is one of these subjects, and not only must it hang, but hang at the same angle as on the tree, if a natural photograph is to be obtained. Indeed, the artistic worker will in every case try to so dispose the flowers he is endeavoring to perpetuate upon glass as to give a natural air to them. "Bouquets" are usually stiff and abominable, uniless they closely follow nature's disposi= tion of bloom, bud and leaf.

In photographing these difficult pendent subjects, I have usually found it best to use a vase, kept out of the composition if at all possible, though sometimes it must show. Sometimes, too, the flowers are secured on longer branches, and tied in a natural position, the branch running off the side of the plate. A little experience will soon show the worker of artistic tendencies how many beautiful things he can do, if he mixes much brains with his developer, plates and camera.

I cannot leave this section of flower-

Suggestions. photography in natural size without suggesting some lines of work. The earnest amateur will soon be delighted with what can be done, and he will want a definite object. It is easily had. Take up a whole family - the rose, for instance. Follow it from the lovely sweet-brier through the glories of reds, whites, pinks and yellows of every form and style and fragrance, clear to the newer single types, as the dainty multiflora, the royal Rugosa, the vigorous Wichuraiana. Take up the blossoms of fruit trees, and get keen enjoyment out of cherry, apple, pear, plum and quince flowers, finding many difficulties and much satisfaction. Or hunt up the common, yet unobserved flowers of our native trees-the white maple in early March, the American elm right after it, the red and the Norway maples, the catkins of birch and poplar, the gorgeous horse chestnut, the lovely dogwoods. I well remember the enjoyment I had in mystifying friends with a photograph of the flowers of the Norway maple, which all admired, and none recognized. And the exquisite yellow, green and orange flowers of our native tulip tree, the Liriodendron, when photographed in true values, will also astonish and please. The splendid white blossoms of the dogwood are attractive, and difficult enough.

The "promised land" is open to every nature-lover; go up and possess it. No aristocratic orchids need apply; this is a democracy of beauty for all. 
Flowers in

Their Natural Haunts.

Addressing now the third division of our subject-though it must be confessed that the division lines are extremely vague, and that much mentioned in each section is equally applicable to all-we take up perhaps the most interesting part of floral photography: the picturing of the blooms where they live, outdoors, as nature (sometimes assisted i) places them. For, however well we may succeed in photographing compositions and combinations, and however excellent may be the technique in working specimens in life size, we miss the greatest beauty - that of environment and situation. For decorative effect the combinations are most charming, and the full-size studies not only have often a special beauty but a decided scientific value. It is where the wild things grow, however, that they are most fitting and most attractive, and it is in their natural situations and environments that we nuw wish to study them photographically.

It is by no means simple landscape photography that we take up, for in nearly every instance the landscape must be subordinated to the main feature. We must have in the picture, if it is to be a picture and not a mere photograph, a iewel of nature in a setting of nature's devising ; and this may well apply, too, to the locations where the art of the landscape architect has supple mented nature, for the aim of any true artist who works with God's plants and trees instead of man's paints and brushes, is always to produce natural effects. That is, truly artistic planting, be it ever so simple or ever so elaborate, is successful just to the degree in which the new conditions established stimulate some of naturels varied situations. Thus we may joy in photographing a wild thing-or a cultivated one, either-carefully and lovingly placed in an appropriate spot on the estate of a millionaire, just as much as if we found it in the deepest woods. Plants know when they are loved the finest " wild" flowers I know are suitably and happily located in an "American Garden," not forty minutes distant from Philadelphia's City Hall.

For outdoor work, we must of course

Tripods. use a tripod-I shall advocate no "snapshot" work. Provide one which is light but rigid, which sticks where it is set, will not vibrate $\mathrm{n}$ a high wind, and which has a broad top to give a firm support to the camera, together with an unforgetable, undetachable tripod screw. The tripod must not collapse easily, but should close up to a mere baton. Provide 


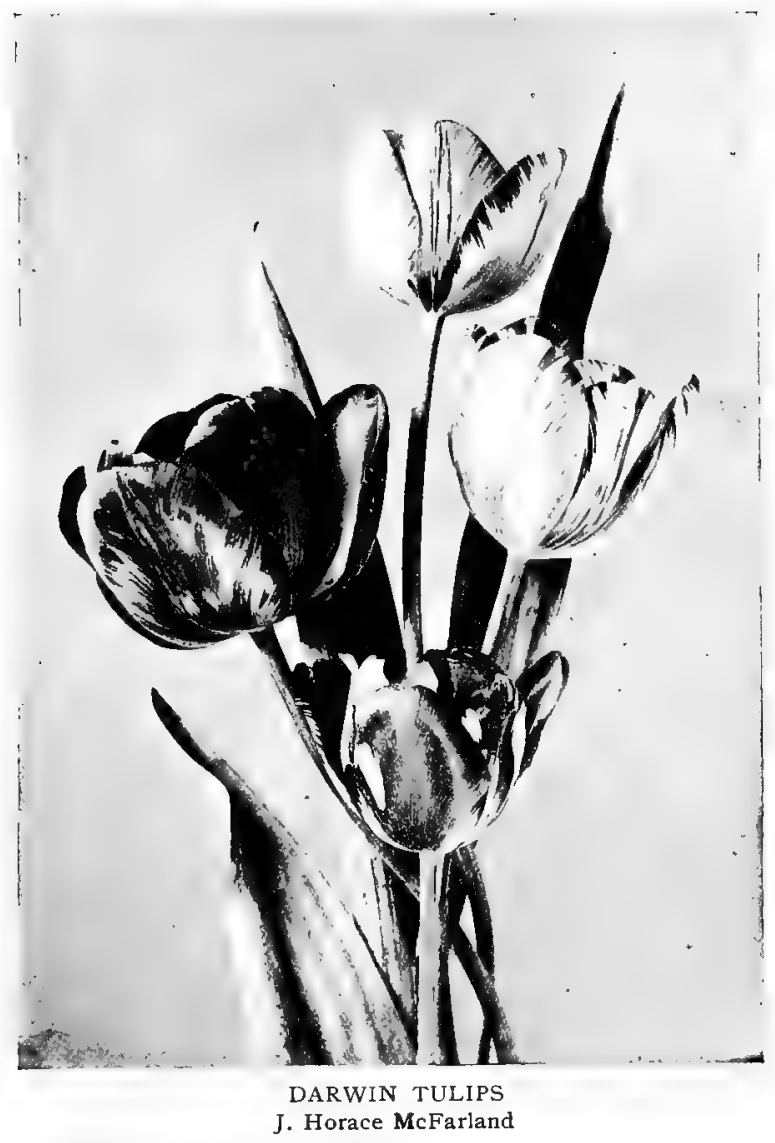


such a paragon of tripods, I say, if you can- $\mathrm{I}$ have never yet found it! But come as near to it as possible.

For outdoor work, the long-focus cam-

Camera. era box of the folding type is by far the best. One which has space enough in its back to comfortably carry a felt case or bag with three holders is best ; for long experience and much "toting" has taught me that the less separate items one has to carry, the better! The felt bag, by the way, is one of those unobtrusive little things which are really of great importance. What avails one's best skill if the plateholder has been "sunned" a bit too much, or if a sudden shower wets the slides? The bag should be made of a rectangular shape, of heavy dark felt, not flannel, with a separate division for each holder, and a deep flap to tuck in the front. It is a tailor's job to make one, and I have paid 50 cents for each one I use, furnishing the material, and the holders, around which the bag is tashioned. It affords an easy means of carrying three holders, and may be laid on damp grass, or even for a time in the full sun, with impunity.

Another important trifle for field work is the focusing cloth. Avoid the rubber abominations which have nothing to recommend them but lightness. Get a piece of black “ladies' cloth," about $\mathrm{x} / 4$ yards square, selecting a fabric that is light, but strong and closely woven. This will serve its purpose of excluding light while focusing is being done, and will also turn a heavy shower on occasion, as well as provide an available background.

For an objective, the same wide-angle

The Lens. lens before recommended is the most desirable, though often a lens of normal focus is very useful, and sometimes the longer focus of the single combination will reach after a fine flower in an unapproachable place.

I am aware of my heresy in suggesting a wide-angle lens for outdoor work, but it should be remembered that in this case it is not used at universal focus to bring in the whole countryside. On the contrary, its special function is to emphasize the near-by plants or flower clusters we are after, and to subdue the importance of the background. Paradoxical as it may seem, the wide-angle is also quicker in this work than its aristocratic brother of longer focus and higher price! If we work, for instance, upon a rose-bush at a distance of five or six feet, with a lens of to inches focus, and there are trees in the distance, or other shrubs, we will need to stop down the lens to $f / 43$ or thereabout, to get away from the nasty "shot- 
hole" appearance of the background; and if there is wind going, we have trouble on our hands and probably spoiled plates in our holders! Now, with a 7 -inch lens, the background will be soft without painful sharpness, and also subdued in size, at an opening of $f / 22$, taking not over one-third the exposure of the other lens.

For field work, isochromatic plates are almost an abso* lute necessity, because there is so much yellow to be considered. It will also tend to better results, and render one more independent of the direction of the light, if the plates are "backed," to prevent halation, unless a doublecoated orthochromatic plate, such as the Orthonon, be used for the same purpose.

I have so much eñjoyed a formula for Plate Backing. backing (picked up in one of the annuals) which works most perfectly, and is free from the messiness and pinhole certainties of the caramel and other smear compositions, that I append it in full. Shake $1 / 2$ oz. powdered rastile soap in Io $\mathrm{oz} .95^{\circ}$ alcohol, repeatedly, until partly or fully dissolved. (It is better to keep this on hand a week or more ahead, shaking the bottle when you see it. The solution is ready or use when half the soap is taken up.) Filter off $2 \mathrm{oz}$. of the soap solution, and add to it ro grains of erythrosin and ro grains of aurin, which will dissolve promptly. Paint the backs of the plates with this, and allow to dry. Use a very faint red light and much care in applying the coating, which is colorless in red light, but will be very apparent on development if it gets on the face! My plan is to coat the pair of plates just as it is taken from the package, without exposing the face at all.

Wipe off the backing with a wad of wet cotton before development, and rinse the whole plate carefully in a tray of clean water - all in very faint red light, of course.

The

Ray-Filter. I per cent. solution as recommended, of blue and lavender he may find, and will also enable him to get enchanting white clouds in a blue sky for his background occasionally. There are also now available good ray-filters of stained gelatine. One should be chosen of light or medium tone.

For this outdoor work, weather condi-

Weather

Conditions. tions must be considered. It is very hard to get any satisfactory pictures in bright sunlight, and it is best not to start for a photographic jaunt on a day promising an unclouded sky. If, however, the work must be done on such a day-and very many of 
the flower jewels wait no man's pleasure for the time of their maturity and rapid decadence-work early in the morning or late in the afternoon, when the sun's rays do not fall so directly and there is more diffused light. Also, give at such times quite full exposures, and develop carefully for density, using a restrained developer. The theory is that by moderate over-exposure the density of the high lights is reduced and the details brought out in the shadows, and the proper development preserves a suitable balance in the negative.

The ideal day for outdoor flower-photography is one in which the sky is overcast with fleecy clouds, or one with what is known as "hazy sun." There may be good work done, with care, on very dark, cloudy days, though there is a lack of snap where the light is so much reduced and diffused that no shadows are cast. Of course, a heavy wind destroys any possibility of success, though even on windy days there are often lulls which will permit of successful exposures, I have memories of long waits, however, with no results save vexation! On Long Island the wind blows and blows, as I found out after waiting bulb in hand for a long half hour, the lens focused on a beautiful clethra. In despair, at last, I made the exposure, and lost a plate, of course.

The direction of the light is of much

Illumination. importance. Photographing against the sun, in a diffused light, often gives charming effects; but if detail is wanted, don't do it! All the light tones of flowers are so very much lighter than the foliage, and reflect so much more light, that the chief difficulty is to get detail in the foliage without over-exposing the flowers. If to this trouble is added the further difficulty of having the foliage in shadow, it is likely to be Iepresented in the negative principally by clear glass, which is another name for "mud" in a picture. Therefore, if detail is wanted, and it usually is, we must photograph with the sun at our backs, or somewhat to right or left. This is necessary also on cloudy days, when the sun casts no apparent shadow, for even on such a day we will soon discover that the preponderance of light is strong'y from the direction of the luminary whose actinic rays must do our painting for us. And if we are working in natural surroundings, the great importance of the direction of the light must not be overlooked.

I have several times endeavored, owing to the conditions, to photograph specimen coniferous evergreenspines, hemlocks, and the like-against the light, on cloudy days, giving very long exposures to compensate for the 


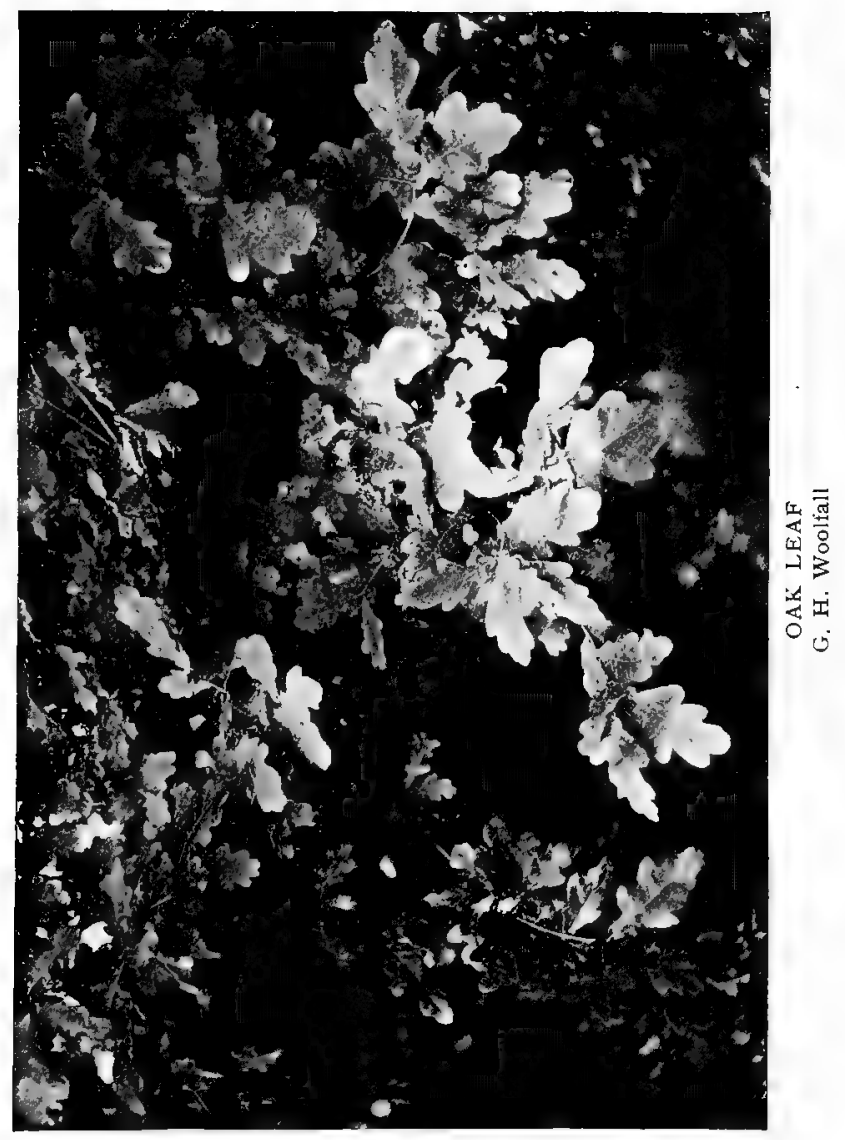




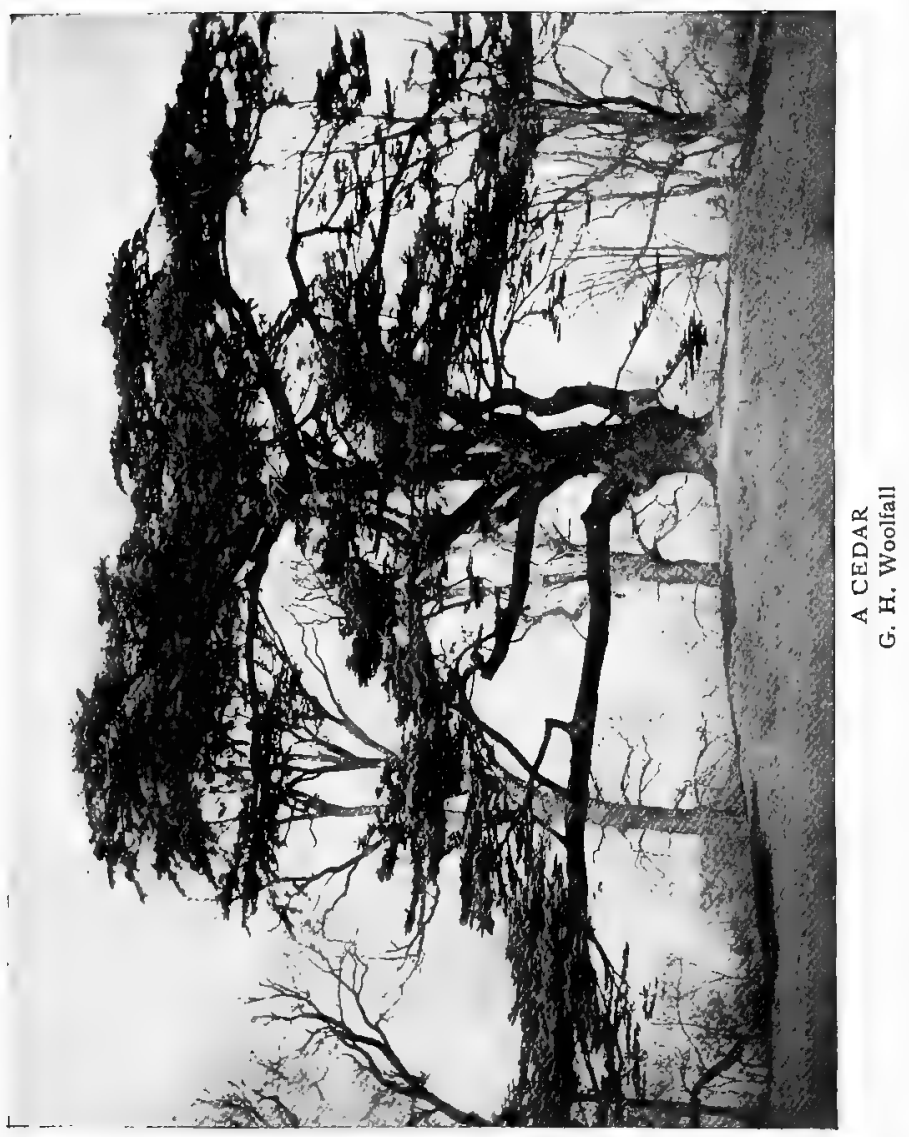


wrong direction. The failures were uniform, and I was further convinced that to secure detail in green foliage, the light must be shining right into the side photographed.

The middle hours of the day are not good for this work. Then the top light is especially strong, over-illuminating the flowers, and tending toward harsh high-light spots on the upper leaves, with correspondingly dense shadows below. The early morning hours are especially good; I have made successful rose pictures while the dew-drops were yet resting on the petals of the rose, just before sunrise. The long evening light is also very favorable, though much slower. Another important point is that even in windy weather there is usually a hush in the morning, and again in the evening, during which delicate flowers and foliage which have been tetering in a tantalizing manner all the day, may be caught napping. Indeed, it is worth much preparation and sacrifice to arrange for undisturbed opportunity, especially during the hours of daylight before ten o'clock in the morning. Many times have I had good reason to deeply regret the precious moments wasted on breakfast and courtesy, while the beautiful morning light was fleeting and the wind was rising to vex me!

That matter of wind-it is a vexing

Zephyrs. one! Often a zephyr so gentle that it utterly fails to fan the perspiring forehead of the photographer is sufficient to keep up a continual movement of the delicately poised flower cluster he is after. He will think of using the focusing cloth as a wind-break, perhaps, and will then discover that the offending breeze seems to come from nowhere, for he can't shut it off ! The only thing to do is to wait for the quiet moment ; and when the patience is all gone, and the temptation is to make an exposure anyway, in despair, don't! Keep on waiting! Better one good negative in a half-day than a half-dozen bringing the regretful thought, "It might have been!"

Practical

Work.

Now, we have had enough preparation, surely-let us sally forth with camera and tripod, plates and lens, on a cloudy day in early spring. We think of the beauties of the apple-blossoms, and we resolve that the apple-blossom picture shall be ours. We come to the old orchard, and are at once amazed at the wealth of material. We are wanting.pictures of the blossoms, not of the trees, which, when reduced to the limits of our plates, are a mere blotch of white, perhaps against a sky that is also white, 
actinically, at least. We consequently avoid the mass, and find a projecting branch at the edge of the orchard, which we can bring on the ground-glass so that it will not have other blossom-laden twigs as a background. We consider the exquisite cups of pink and white, and perhaps we break the rule of photographing with the light, for the sake of the shadows we can get in the flowers, giving them modeling and form. Perhaps a figure is introduced (never with face toward the camera), and a picture breathing of spring is on the ground-glass. The light is quick; we stop down to $f / 22$, wait the still instant, give an exposure of perhaps one-third of a second, and we ought to be happy upon development!

The apple-blossom is a "tame" flower, and we want to photograph those termed "wild." Just about the blossom time we hear of a great display of the "wakerobin," Trillium grandiflorum, on a rocky hillside. Thither we journey, and the sight is gorgeous, for the whole hillside is dotted with the delicate, but large, white and pink blossoms. Here is a different problem, for the tallest plant is not 12 inches high, and our tripod stands fuil 50 inches. We slide in one joint of it all around, spread out widely, throw one leg up almost horizontally against the hillside, tip the camera down, and have the flowers before us. How thankful we are that there are none of man's rigid vertical lines to make apparent the dip from the horizontal of the ground-glass! Now it appears that we don't get any one of the trilliums full in the face, and we proceed to aid nature by tenderly transplanting two or three into eligible locations, carefully arranging them so as to "look natural." A satisfactory view results, and with a much longer exposure to compensate for the trees which surround us, we press the bulb, and the trilliums live again upon development.

Again, later in the year, we strike a glorious mass of the small "soft sunflower," Helionthus mollis. Bright yellow and orange, and dark centres; the ray-filter is needed; we point at the centre of the plant, await the momentary cloud, and a "quick bulb" exposure is enough.

We are entranced at the exquisite flowers of several of the native orchids, Cypripedium pubescens, in rich yellow, and $C$. acaule in deep pink. Long we labor to get the plants and camera in harmony, but only failure results, because the habit of the genus being to locate in isolated clumps amid other low-growing plants, it is well nigh impossible to get a background which will contrast safely with the flowers. Later, we find the way out of 
such troubles by gently transferring the plants to a suitable place in front of a stump or a large rock, and we are happy!

But there is no need to multiply examples, for he who, with blood stirring with the opening of spring, takes his camera and gets "close to Nature's heart" in the search for pictures of her fairest children, will need no directions - his greatest need will be time, time! He will count lost, as I do, that photographic day which he must spend at his work earning a living, and he will get health and enlargement of soul, and many pleasing reminders for the winter days, from those days when his nature sense takes him afield in spite of desk or shop, or even the telling about his "hobby," which I would drop right now with much joy to essay another time at the spring . flowers!

Photographing The photographing of trees is conTrees. nected closely with outdoor flower work, and may be taken up to great advantage by those who get into touch with the dainty blossoms of the field. Indeed, the two sections intermingle, for some of the most beautiful flowers to photograph grow on trees, and to get them in the natural situation, the tree must be considered.

Tree photography is also intertwined with landscape work, though with this difference, that while in the latter the tree is merely a means to an end, an incidental part of the composition, in the former it is the main object, and to be pursued with landscape accessories only.

Decorative There is, too, much to be gained by a

Forms. study of tree forms, or more especially, twig and branch forms, in connection with their decorative value. The wide-awake photographer who once realizes the beauty and individuality of trees and shrubs in their leafless condition, when every twig is traced against the sky, will never complain that winter shuts off his work and pleasure. Indeed, many careful workers are of the opinion that the winter garb of the trees is far more interesting. Many valuable suggestions concerning "Decorative Natural Forms" may be found in the second part of this little book and the covers of outdoor magazines.

There are many charming effects within reach of the enthusiast who shoulders his camera on a snowy winter's day. The varied play of the light on the trunks and twigs, as one looks at the tree's form, against, or quartering to the sun, is most interesting, especially when considered with relation to the sky and cloud values 


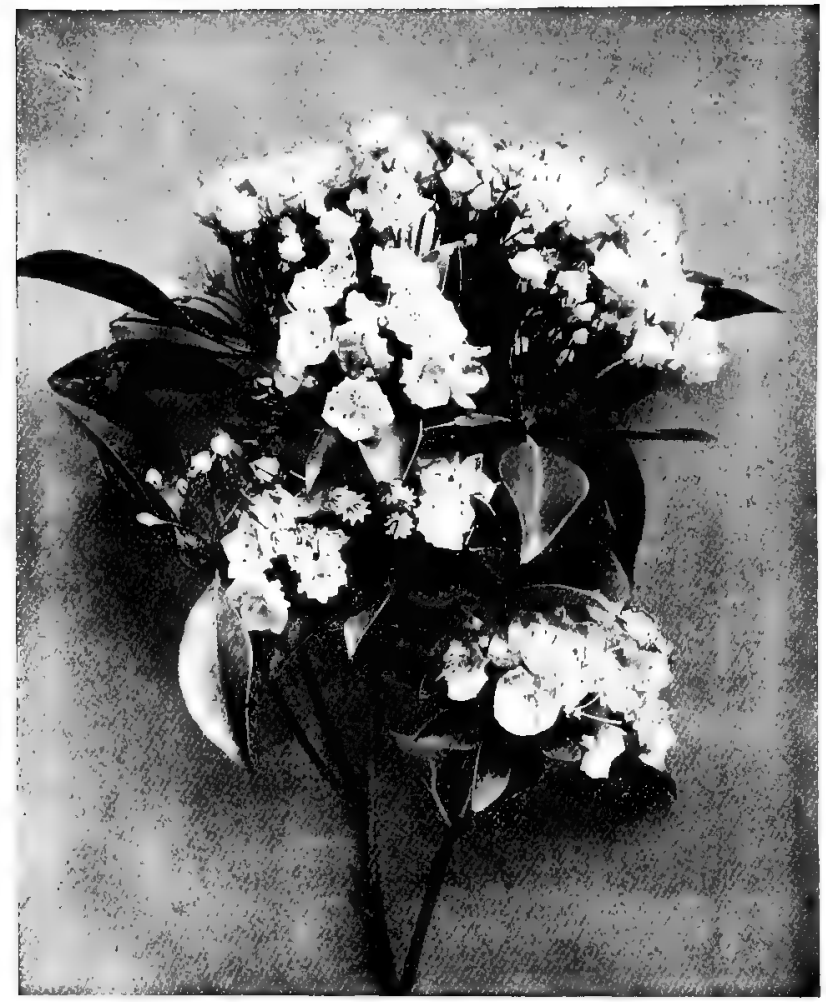

MOUNTAIN LAUREL (Kalmia latifolia) Henry Troth 
Extreme nicety in exposure will help immensely in obtaining satisfactory results.

For this outdoor tree work the outfit previously recommended, as to camera and tripod, will suffice. The wideangle lens, too, is again most useful; for we want our main object, the tree or shrub or bush, largest, with the landscape diminishing in size and importance. In this case, then, the chief objection to the wide-angle lens for landscape work becomes its main virtue.

Isochromatic plates are an advantage, because in the summer's work we have many shades of yellow and green to deal with. A ray-filter will help very strongly, when there are clouds in the sky ; and usually the lengthened exposure will be no detriment.

In summer tree photography the main Wind. trouble is from the wind. Leaves are delicately hung, and often the perspiring worker on the ground, waiting in impatience for the "going in the tree-tops" to cease, wonders where the twigs find the zephyrs which persistently fan them while missing his dripping forehead! It is a question of waiting, often; but it is worth noting that there is almost always a settling down, a lull, after a sharp blow of a moment or so. Wait on this, bulb in hand, quick plate ready, and you may' get the fraction of second's stillness which is needed.

The question of exposure is totally

Exposure. dependent upon the objects and the light, of course, but one thing may be noted, and that is, that deep green trees, nearby, take two to three times the exposure of an open landscape; and they are also far better rendered upon a non-halation or "backed" plate. Another thing, previously mentioned in these pages, but again emphasized now, is the absolute necessity of working upon heavy foliage masses or deep evergreen trees with the light streaming upon the main object. No length of exposure will compensate for the wrong direction, and the negative made against the light, with a great pine as a principal point, will be a failure. Of course, I must not by this be understood to argue against evening views, sunsets and the like, with trees between the camera and the light. Such views, often delightful, are not primarily tree pictures, and my point holds.

In photographing for tree features, however, the landscape need not be neglected, and a main necessity for an agreeable result is the proper balancing of the composition. Often an apparently irrelevant object will be just 
the thing to enforce the value of the main feature. In this, as in all other photographic work, intelligent, and not arbitrary or didactic art training, is of enormous value, and constant study of the conditions, without exposing plates, will tend toward continuous success when exposures are made.

Trees in blossom are delightful to look at, and not easy to photograph. The apple blossom melts so easily and indistinguishably into the white sky! Here again comes into play judgment and a ray-filter, clouds and the right direction.

Fruit trees in fruit are almost hopeless. The brilliant red cherry is, alas, a flat black photographically. Separate twigs of berry-bearing fruits, however, are often charmingly photographed in the studio, with decorative intent. Occasionally one can find a branch of a fruiting tree in such position as to get it against the sky, and then a good thing may result.

The four branches of our subject, treated in the foregoing pages, are intimately interwoven, and I can only hope that the hints presented may smooth the path of some nature-lovers who may take up the delightful work.

Reproducing It is but natural, despite any satisfacColor sire to see reproduced and hold the actual colors of nature. Particularly is this desire apparent when the colors, tints, shadings and mottlings of flowers are considered, or when one thinks of how the shading glories of the greens of nature make supremely attractive the brighter hues that are contrasted with them in a rose, a peony, an iris or a canna.

That practically efficient color photography is sure to be accomplished admits of no doubt. That it has not been worked out in any such relative completeness as that included in "black-and-white" photography is also certain, up to the date of this revision.

But colors have been captured on the photographic plate, and held there in faithful purity, by the marvelous autochrome process perfected through the patient and painstaking work of the Messrs. Lumiere. An autochrome, well made, holds every tint, shade, color and luster of the object photographed, in a transparency, appreciable in all its perfection only as seen by transmitted light, reflected from a white cloud. It has not been practicably duplicated or printed on paper, and is therefore an original record only. It is here mentioned as a record rather than as a present facility. 


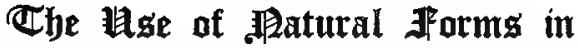 Secoratíne Abotography}

The art, or practice, of conventional decoration has had many vicissitudes, especially in America. This land, quick to respond to all influences that seem new, whether desirable or not, and with its population made up in some part from every land of all the earth, has had its crazes or vogues of decoration. Sometimes these vogues have pervaded everything from dress to architecture, and while the former has reacted immediately from an enormity, there yet remain to be seen mournful examples of "Eastlake" effect in grotesque houses. The recoil from the "Queen Anne" type is fully within remembrance, as well, and these ornate and specialized architectural forms, with many others I need not name, have always had a strikingly distinct effect on decorative procedure. Wall-papers, picture-hanging, linen, bookcovers, car interiors and all the familiar surroundings of our daily life take form from the prevailing decorative thought, whether it be true or false.

It is possibly apropos to say that these words are written in a Pullman sleeping-car, the second one in which I have found a shelf to attempt rest upon in three days. The other one, in the Canadian service, was of the vintage of 1890 , and full of nameless but not formless horrors of wooden, woollen and mosaic ornamentation, calculated to banish rest in the daytime and to induce nightmare when sleep was attempted. The one in which I write shows a vast improvement in line, form and color, and it is not too much to ex- 
pect that eventually the feeling for true simplicity will reach the builders of Pullman cars so that they will set real comfort for the eye before garish display.

It is undoubtedly to the words and works of Ruskin and of Morris that this modern tendency to settle down into forms of simplicity and true beauty is due. The one taught the principles; the other, by cunning and strong handiwork, introduced the practice.

Decorative

Photography

Overlooked

With these conditions existing, it is perhaps as well that the possibilities of photography as a purely decorative agency, apart from relation to pictorial work, have been overlooked. That they have not been largely used is certain; and it is just as certain that, as the wonderful process of photography comes into play, it will become the most facile and familiar tool of the decorative worker.

The subject of decorative photography is so broad, and so new, that its adequate treatment is certainly beyond not only my present opportunity but my ability. I can, therefore, but hint, as efficiently as I am able, at the fascinating lines which open before the consideration of photography as a decorative agent, while hoping that there will follow, as the practices of the art may develop, a more efficient treatment of it.

Before taking up the detail of the

The Field work, it will be best to consider briefly the field. What is the field of decorative photography, I ask? I may properly answer, Every truly decorative surrounding of modern life! This in-. cludes, inevitably, nearly all the surroundings of that life, for the time is long past when bare utility is the only end and aim. We no longer rest satisfied that the things we deal with are useful and strong, or ingenious and comprehensive, or sanitary and comfortable. They must be beautiful, as well; and in this insistence we but hark to ages of antiquity and learn again the ofttaught lessons set forth to us by history and by mythology.

Modern decorative art deals with all materials, used in all places; and for much of the work of designing, photography may be made useful. Let us glance over a 
few of the fields in which it offers facility, but for a moment let us first mention a few technical essentials.

While the inexperienced amateur can

Technical

Essentials do something in decorative work, it is obviously better that one who aspires to produce unique or pleasing decorative results in photography should have a fair acquaintance with the camera and its handling. The ability to make photographs of the natural size of certain objects, sharply defined, with a well-chosen background, is essential to success in this field.

For the most part, the same methods and apparatus are desirable, as were suggested in the preceding monograph on Photographing Flowers and Trees. A camera with plenty of bellows extension, so that objects may be easily photographed full size, is important, and it should be fitted with a lens of moderately short focus-as, for instance, a seven-inch lens for a $5 \times 7$ camera-in order that objects may be conveniently focused in natural size. A camera-stand for maintaining the camera in a vertical relation to a horizontally placed plate-glass exposing platform is nearly essential to this work, and if that stand is portable, and with its parts adjustable at various angles from the vertical, so much the better. A collection of sheets of cardboard of various colors from black to white, to use as backgrounds, is necessary, for in this work control of the background is essential to proper results.

The Handling of Flowers

As many of the subjects that the present writer, at least, has to suggest for decorative treatment are flowers, leaves, fruits, etc.--parts of the growing plant or treesome acquaintance with prompt and successful handling of these objects will be helpful. It is, indeed, to an appreciation of the almost untouched wealth of motive and potential design in these natural objects that the writing of this monograph is due. The suggestions here made, and applied in a limited practice to flowers, ferns, fruits and the like, may also be applied to other objects - a design worked out with wire nails may be as pleasing for a certain use as one taking its motive from a violet may be for another use. 
The suggestions given on earlier pages will assist the worker who is desirous of pursuing this subject in the matters of technique and of apparatus, and will guide him past some of the difficulties that might otherwise discourage him.

The Place

In passing from the questions of apto Work paratus, special methods and desirable previous experience, it may be in place to say that while this work of decorative photographic design composition may be pursued anywhere that light conditions will permit, a cool, well-lighted north room, with, if possible, light from either east or west to supplement and qualify the north light, will be most serviceable. In a cool room, leaves and flowers will longer retain their freshness. I have seen the very best efforts fail in a city top-floor skylight studio, with a summer temperature requiring three figures of Fahrenheit's scale to express! Indeed, it is only telling the bare truth to say that the elusive, delusive, fascinating and expensive "three-color" process, as used commercially, would be far more practicable for natural objects than for anything else, if the regulation studio where the ignis fatuus is pursued was not, almost invariably, a combination of the temperature of a furnace with the fumes of a chemical factory. Once upon a time, with everything of skili, experience and apparatus otherwise favorable, I saw carnations of full freshness fairly melt in the fearful atmosphere of heat and collodion fumes before they could even be focused upon.

As a contrast, I remember one July day, with an average temperature of $98^{\circ}$ in the shade, on which I successfully photographed, in full size, the very delicate flowers of the Japanese iris; but I worked in a cellar, just under the open doors, the difference of nearly twenty degrees in temperature meaning life for the flowers, comfort for the worker, and results worth while.

But preliminaries of photographic

Book Covers technique hinted at, let us take up a concrete subject. Nothing, it seems to me, presents a better opportunity for photographic design than a book cover. Under modern publishing conditions, few books, save those for technical or 


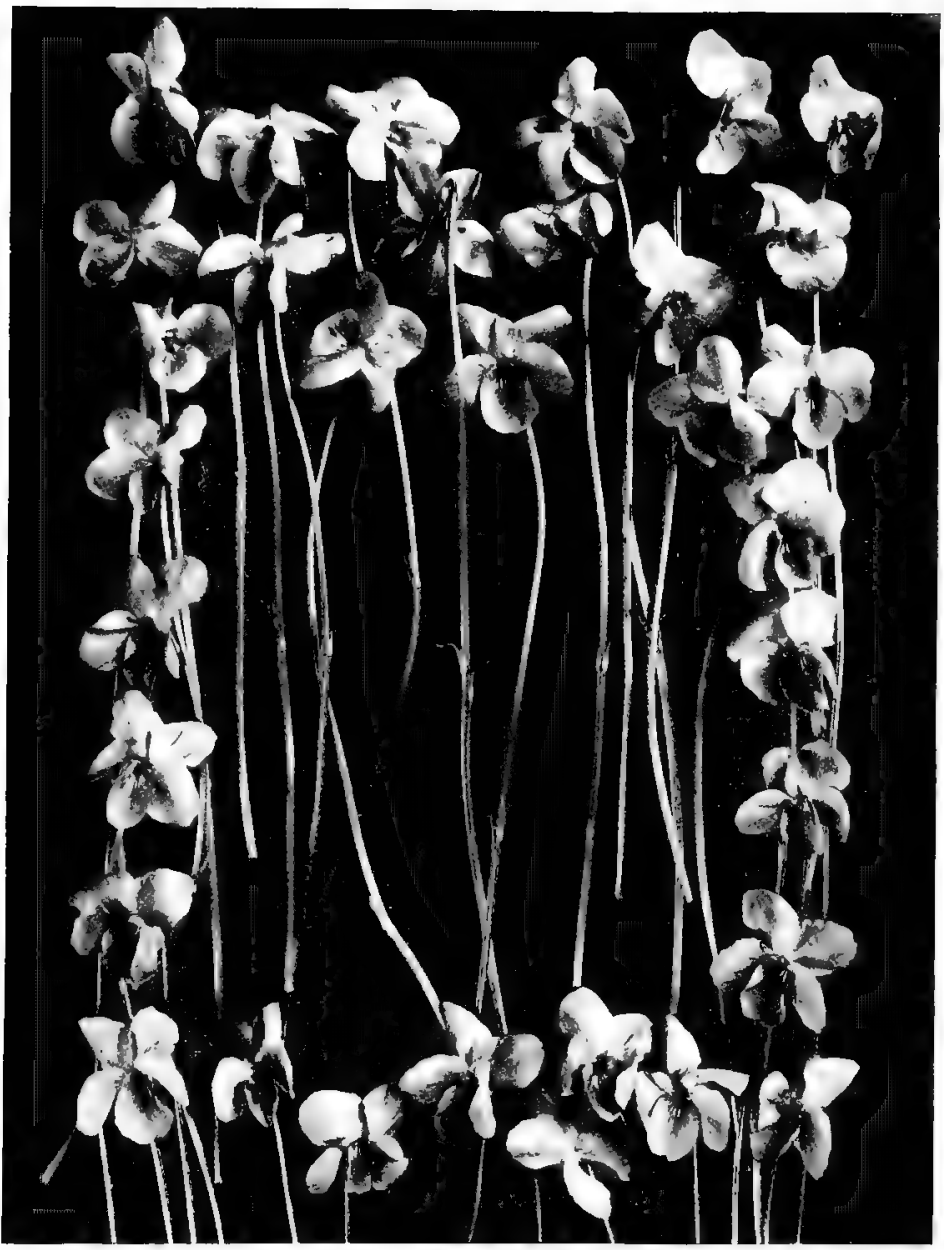

Many of the smaller fowers fall happily into attractive designs for book covers, etc. See page 59. 


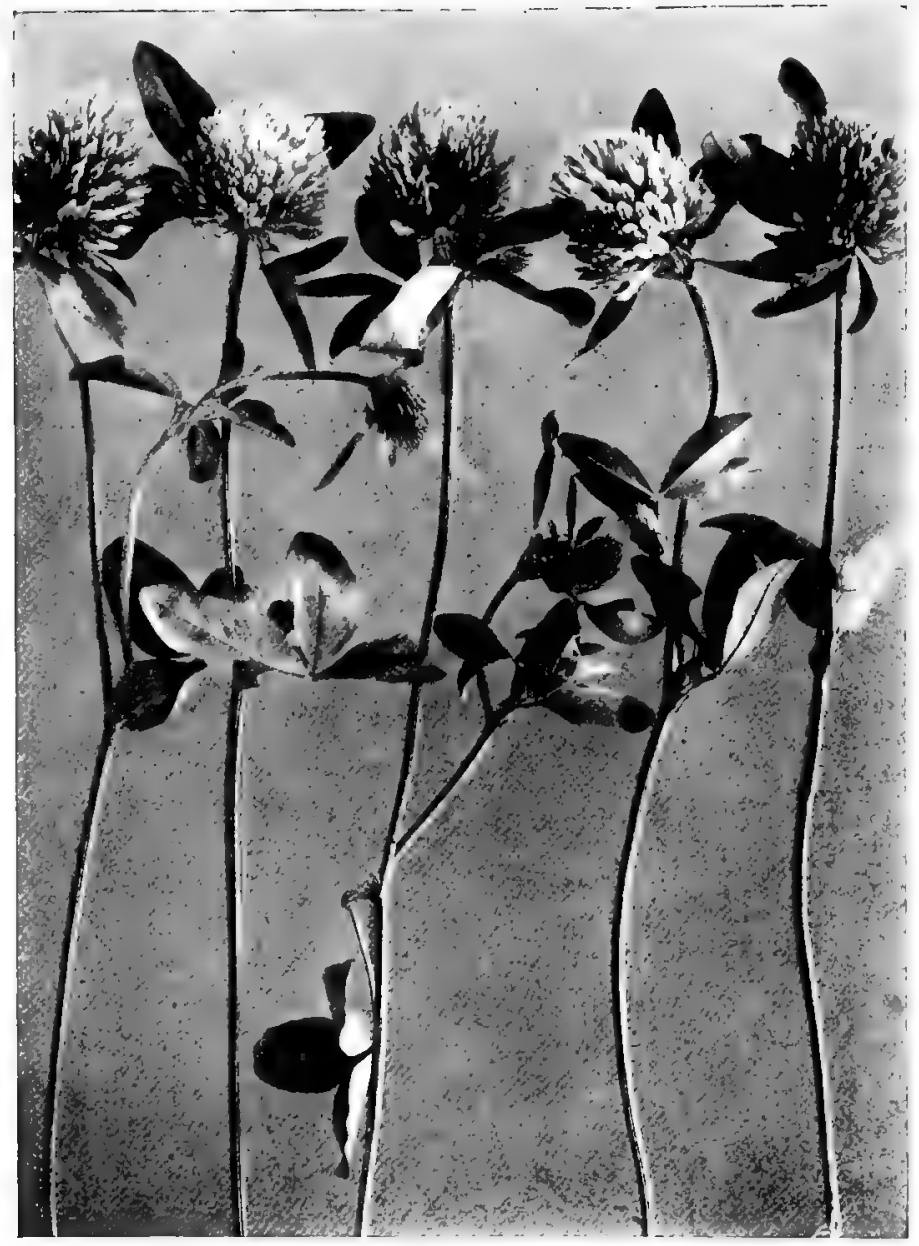

Even clover-heads, skilfully arranged, offer pictorial possibilities for book covers, see page 59. 
school use, have plain covers. Design is the rule, and not the exception. Consider, then, the applicability of the thousand and one natural ideas for book-covers; note how well the oak-leaf, the acorn, the violet, the pansy, the dandelion, the maple-seed, or "samara," the cherry, the chestnut and an almost infinite extension of these familiar objects will adapt themselves to a relatively conventional treatment for design.

A decision should be made at the beginning of the designing effort as to whether the attempt will be to use the branch, twig or cluster as a whole, or to take the flowers, pods, acorns, or whatever the motive be, for separate conventionalizing. Thus, is the book-cover to show a rose cluster, with leaves, buds and flowers, or is it to be an arrangement in separated buds or flowers alone?

The violet scheme shown on page 57 is a hint for the use of comparatively small flowers. While the field of design precludes nothing that is agreeably decorative, it will be found that the usual cluster or bunching arrangement is hardly applicable. Laying out the subjects-violets, for instance-in that regularity of form called conventional, will probably be found more agreeable.

Laying Out Just here may well be given a few the Work points on the way to proceed. Let us presume that it is a book-cover of the size of the ordinary duodecimo novel we are designing, and that we are working with clover-heads, which we propose to reduce to two-thirds natural size; that also the camera is on the vertical stand, and the plate-glass exposing platform is before us. We first arrange a limit of size, either by cutting out a properly proportioned rectangle* from a sheet of pasteboard of any character,

*A simple means of obtaining proper proportion is to add to length and width in equal ratio. If the design desired is to be $4 \times 6$ inches, the "lay-out" may be $6 \times 9$ inches, which will "photograph down" to $4 \times 6$ by one-third reduction. Or, if a diagonal line be drawn from, say, the lower left to the upper right corner of the book-cover rectangle, the point at which the upper right corner of any larger or smaller rectangle intersects this line will give exact proportion. 
or by laying strips of wood or card on the glass to frame in the proposed dimensions, taking care in so doing that we are working from the lens as a center, so that our composition will come on the ground-glass properly. This done, and tested by looking at the arrangement on the ground-glass to note our exact limitations, we proceed to lay the flowers according to the idea that has been conceived for the design. Focusing should be done at once, so that the progress of the composition may be readily examined. To focus full size, or nearly so, is easier if the precaution is taken to use a sharp line to focus upon.

How to Focus

A little device for this purpose is Sharply

described and illustrated on page 33 , but any available scrap of printing may be used, if it has sharp, well-defined hair-lines on it. Place the scrap, not on the highest point-nearest the camera-but a little below that, observing with the lens "wide open." As the focus deepens both ways when a smaller stop is used, the best average defnition is thus obtained, and but little focusing will be required later. To hunt for sharp focus witbout the device or scrap of paper mentioned is to waste much time and risk poor results.

It will be discovered that much alike as all cloverheads seem to be, there are very considerable differences, and several "sides" to the blossoms. With a little experimenting, an agreeable arrangement may be secured, and then inspected on the ground-glass. Sometimes, or rather frequently, it will be necessary to trim out a leaf here, deftly lay another in place there, and otherwise to simplify or complete the arrangement. A leaf may run off the side to advantage, or it may be cut out entirely. Do not lose sight of the fact that you are drawing a certain design with objects and camera rather than with pencil and paper, and that correct handling of lines is just as important as if the implement used was the pencil and not the camera.

Lighting and Backgrounds

The arrangement proving satisfactory, consider next the lighting and the backgrounds. The camera-stand should be readily movable, so that it may receive light at various 


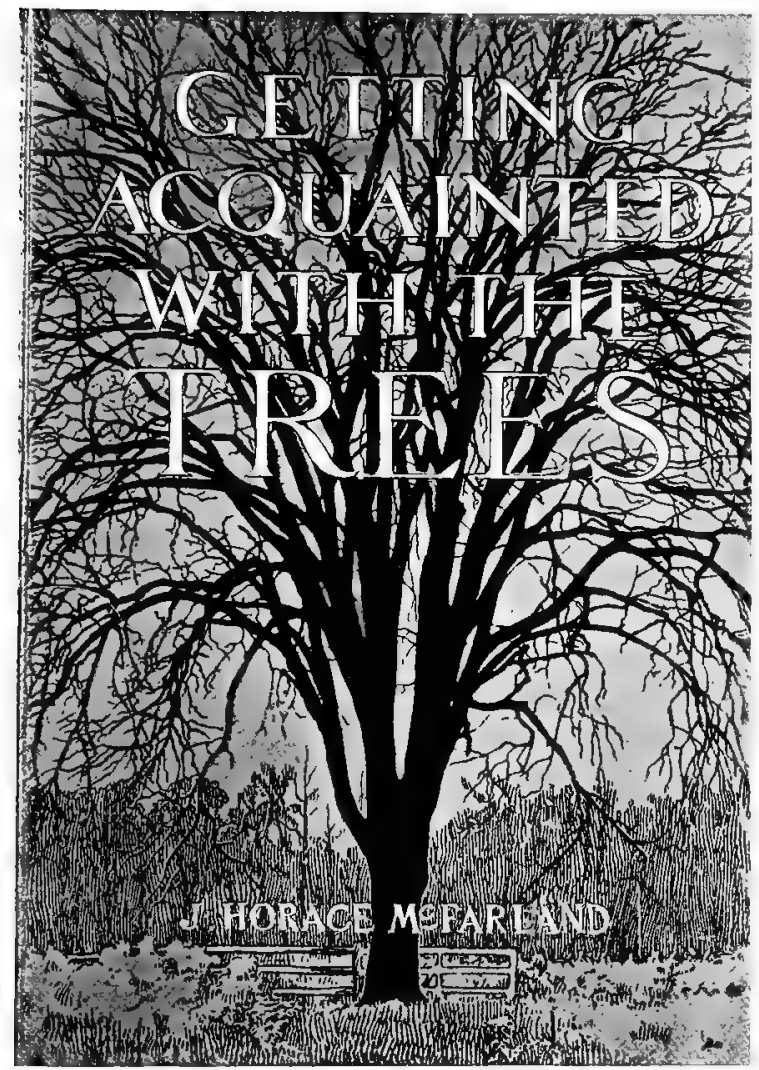

The graceful elm here offered an attractive background for the title of a book on trees. See page 62 .

angles. Usually light from the top or from one side gives the best effect. Sometimes a special idea requires different lighting. The background greatiy influences the result, and must be taken carefully into account. If it be light, the leaves and blossoms will show darker; if it be black, or quite dark, more details will appear on 
the stems and flowers, and they will seem brighter. Sometimes a neutral effect will be desirable. As the various cards used as backgrounds are well below the glass, out of focus, they may be tipped and moved variously to obtain just the effect that seems best. A few plates devoted to pure experiment in lighting, and to the effect of the use of various backgrounds in various ways, will enable the worker to operate with far more certainty than if such experimenting is included in the actual designing.

When all is ready, and the lens stopped down sufficiently to obtain depth and sharpness (usually $f / 22$ or f/32), make the exposure; and by all means develop immediately, so that before the subject has been disturbed, the fixed negative may be considered and replaced with a better one, should it seem advisable. I do not go into detail of exposure here, presuming a certain proficiency on the part of the decorative worker, and only remarking that the negative should by all means tend to softness rather than to contrast, and show full exposure.

Market for

Designs

It is a pertinent 'question to interpolate here, given a satisfactory photograph for the book-cover design, how shall the unacquainted designer use the scheme? The answer is that there is always a demand among publishers for good designs. The properly made photograph is as much in the market as the drawing, and is translated into the brass of the finished book stamp by practically the same mechanical means.

Another method of using a photo-

Using a

Whole Tree graph as a book-cover design is indicated in the outlined elm, shown on page $6 r$. Here the chosen tree was drawn upon the brass after the photograph, and also etched on zinc to use for printing the paper book-wrapper. Endless variations on these simple schemes, for the use of details and of complete trees or plants, will suggest themselves to the worker of any ingenuity.

There is great range of possibility in

Berries and the berry-bearing shrubs and trees-as,

Leaves

for instance, the huckleberry, the dogwood, etc. Lẹves also present chạrming possibilities, 


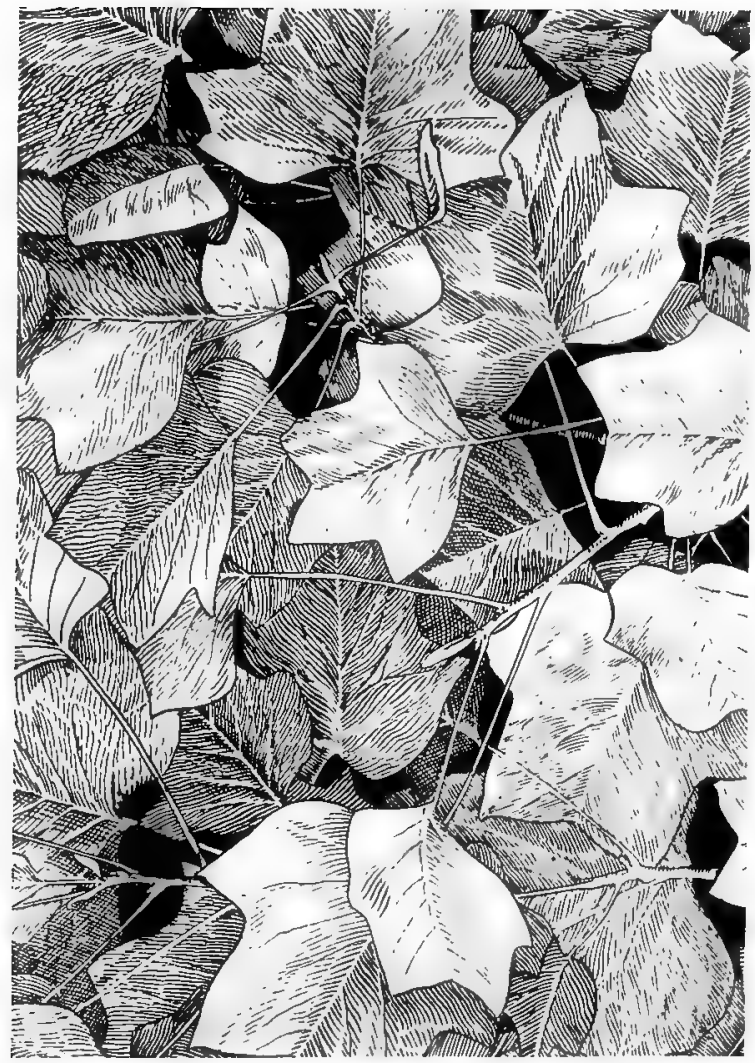

Leaves of trees and many plants have unnumbered possibilities in decorative design for cover or "lining" papers for books, wall papers, printed fabrics and other uses. See page 64.

as witness the design worked out for book "lining papers" - the material used for lining the front and back board covers, and for the facing side of the first "Aly-leaf." In this case the exquisite leaf of the liriodendron, or tulip tree, was used, the photograph being blue-printed, the design drawn in "line" over it, 
the blue-print bleached away, and the resulting blackand-white drawing used as a basis for an ordinary zinc engraving from which to print the "lining papers."

Again I say that endless variations may be made with leaves and blossoms for this interesting use. It will be noted that there is a certain conventional arrangement, but that also the design of the tulip leaf is treated with some freedom.

Another way in which a photographic design may be effectively used is shown in the "half-title" reproduced on page 65. In this case the selected photograph was printed in a gray tone under the black, but the effect here is much the same. It will be seen that the suggestion of a gray or tint undertone use of a decora-. tive motive may be worked almost indefinitely, and with many objects. Where it is not practicable to design for two printings in the book, an approximation of the same effect may be produced by making a gray velox print from the negative-by under-exposure-and then drawing the lettering or other black design upon it with black ink. This will give in the half-tone engraving process a very pleasant and unconventional decorative result. To design for this gray or underprinting method, the negative produced should be fully exposed, and somewhat thin; otherwise it will be difficult to get the gray print to show proper detail. If the worker had the gray method in mind, but also wants a normal print from his composition, he should make two negatives, one somewhat over-exposed.

Magazine

For the making of magazine covers Covers zines have had few other than thotographic covers in photography offers infinite resource. To my knowledge, two prominent magaseveral years - and those not photographic were poor.

In undertaking this form of design, the worker should have in his mind a very clear idea of the end and purpose of his work. A dainty, delicate design may be pleasing in conception, and ever so hard to work out satisfactorily, and it may then be a dead failure, from lack of striking character. In most cases, magazine covers in these days are designed to attract the casual eye when displayed upon a news-stand. 


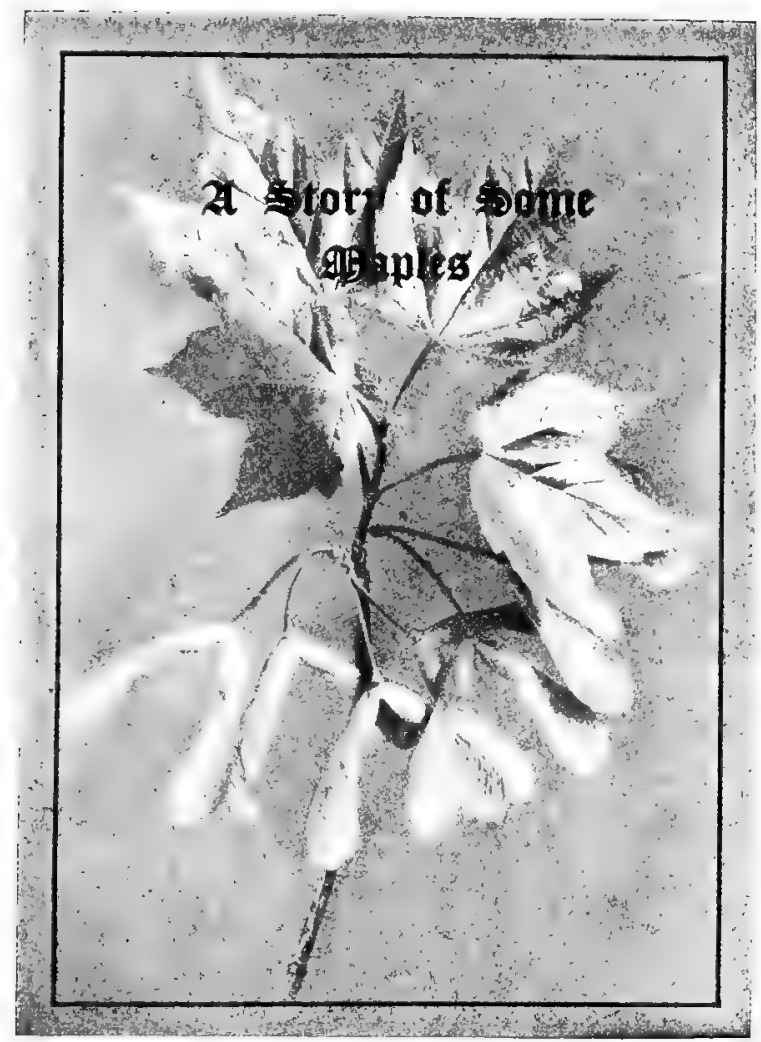

A suggestion for the photographic decoration of the "balf-title" of a book. See page 64 .

"Striking" Indeed, a "good news-stand cover" Designs is earnestly desired and eagerly taken, if even remotely appropriate, by the publisher of any magazine. To have the "striking" quality thus implied, a design must be strong and simple, rather than delicate and refined. I have in mind a cover I designed, using as the motive the exquisite 


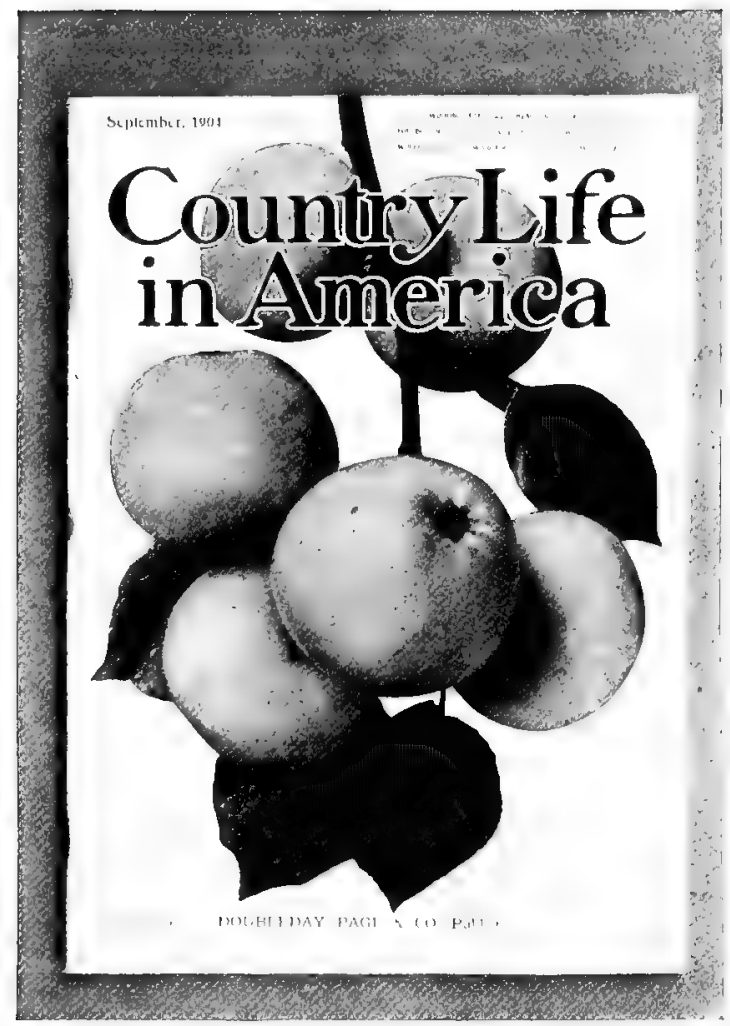

A magazine cover design must demand attention by boldress as well as beauty. See page 67 .

silky pods of the milkweed, as they are found in the fields in late fall or early winter. The result seemed most pleasing-to me-but the "dear public" passed by on the other side in silence, without being attracted to purchase the magazine on which it was used. The design required close attention to disclose its beauty, and it had no appeal at news-stand distance. The lesson, a hard one, was well learned, and ideas there- 
after were tested from a different standpoint. The àpple design, an example, well. shows the attractiveness of size and simplicity; and here is a point needing to be well enforced upon the student. The constant tendency in designing photographically is to overload the detail, or to complicate with too many objects. It is so easy to add another flower, another leaf, another fruit, to fill a temptingly vacant spot, and so difficult to take away, that only failures teach the necessity for reducing detail and complexity. It may be accepted as an axiom that the fewest possible parts will almost surely make the best design.

Another feature in this form of decoPhotography rative photography is the combination and Drawing design, using part photography and part pen or line work, each adapted to the end in view. The daffodils gain in effectiveness by seeming to break through the formal panels, in the case in evidence on page 68 .

The dogwood "Country Calendar" cover on page 69 may be cited as an example of successful designing, the photograph having been helped out by careful drawing. At first, the controlling artist added a formal border that diminished the real effectiveness of the scheme. The publisher realized the need for breadth, and changed it before issue, allowing the original scheme to have effect by discarding the border and permitting the design to cover all the paper surface.

\section{Direction} of Line

In all this work, as before hinted, the simple rules of design must be kept in mind. In every successful composition there is an agreeable direction of line, not the result of chance, by any means. Study any good example, and this intentional trend, inward or outward, but always harmonious, will appear. In using natural objects for photographic designing, the branch or twig or stem will itself often suggest to the eye open for direction the agreeable line. Insensibly, it may be, the line leads toward the object of attention or interest, but be sure that confusing or cross lines, or inharmoniously opposing lines, will, if permitted to dominate, ruin the best decorative conception. 


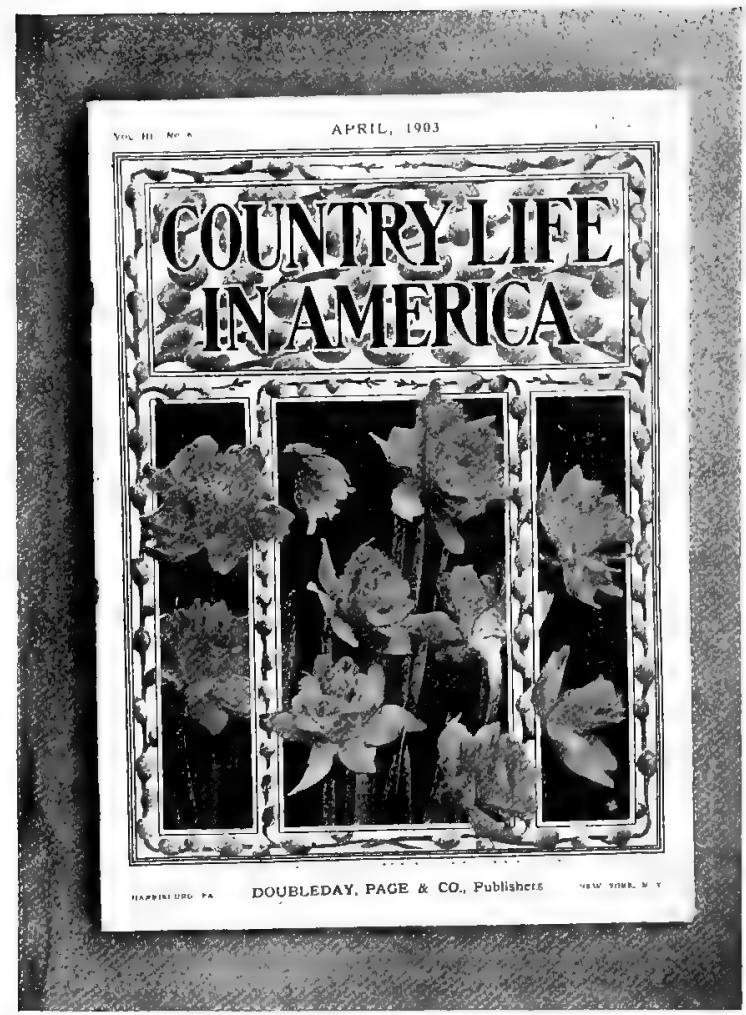

The daffodils gain in effectiveness by seming to break through the formal panels in this design. See page 67

Magazine Another part of modern magazine Headings, etc. work that may be increasingly done by direct or adapted photographic designing is the making of headings of pages or departments, or the decorating of whole pages. A few years ago this was totally out of photographic reach, apparently, but now many excellent examples may be noted. The four "contents" pages shown here will serve to illustrate the 


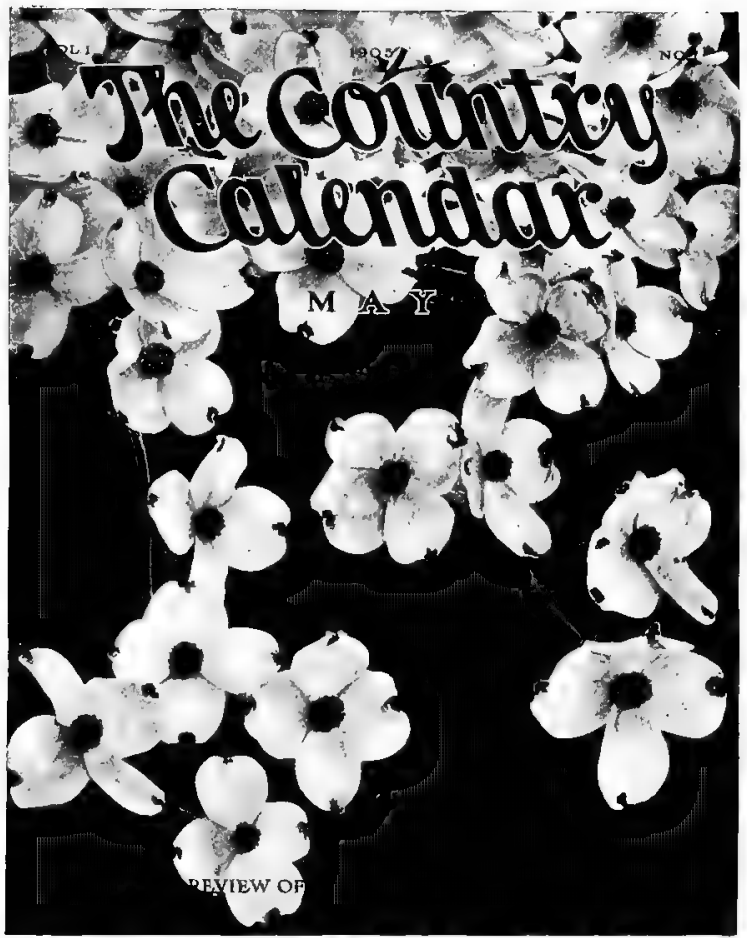

A successful magazine cover in which the design covers the whole surface. See page 67.

idea. The frame of pine-cones was worked out from the branches and cones by careful study of the possibilities in a rather stiff and inflexible subject; and its success is somewhat a contradiction, as the heaviest branch at the top should seemingly have been below. It will be noted, however, that it seems to bind and hold the open central panel-and that was the object. The wheat design ran into the binding of the magazine, and is an example of a most attractive, almost untouched field, among grains and grasses, sedges and 
mosses, for exquisite decorative motives. The strong upright panel of the dog's-tooth violet emphasizes what has been said about direction of line, while the water-

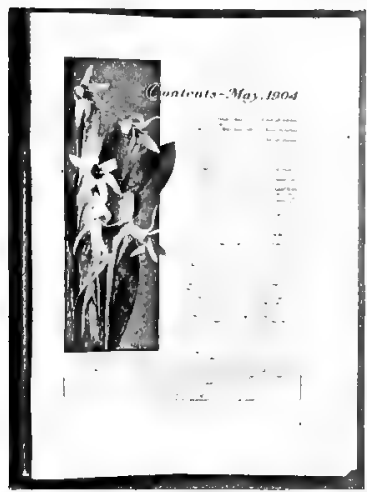
lily heading also presents a scheme of broad horizontal effect, in which advantage had been taken of the natural curves of the lily stems.

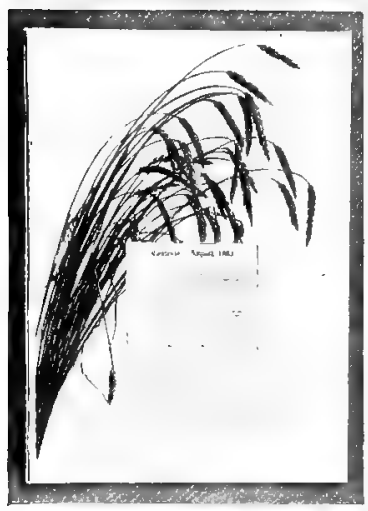

Suggestions for "Contents" pages. See pages $69-70$.

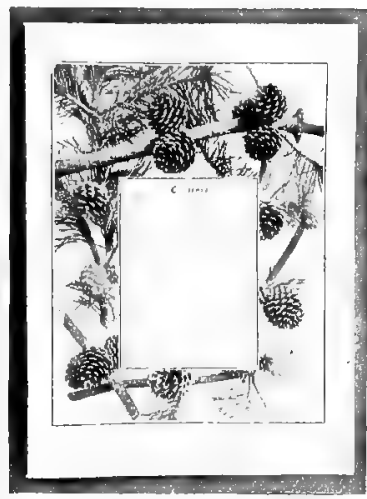

\section{An Open} Mind

In using natural objects, the photographer needs to approach his work with an open mind, $\mathrm{He}$ should, of course, have a very concrete idea as to what he wants, and indeed may often begin with a pencil sketch as a guide; but he should be ready to forget the sketch, whether on paper or in his mind, whenever the natural graces or peculiarities of the 
subject present another or a better thing. Many times, while trying to place in the preconceived arrangement a seemingly reluctant flower or leaf, I have stumbled upon a far better scheme.

Another fertile field for photographic Initials cultivation is in the designing of decorative initials for books and magazines. Here again simplicity is all important, for the initial is

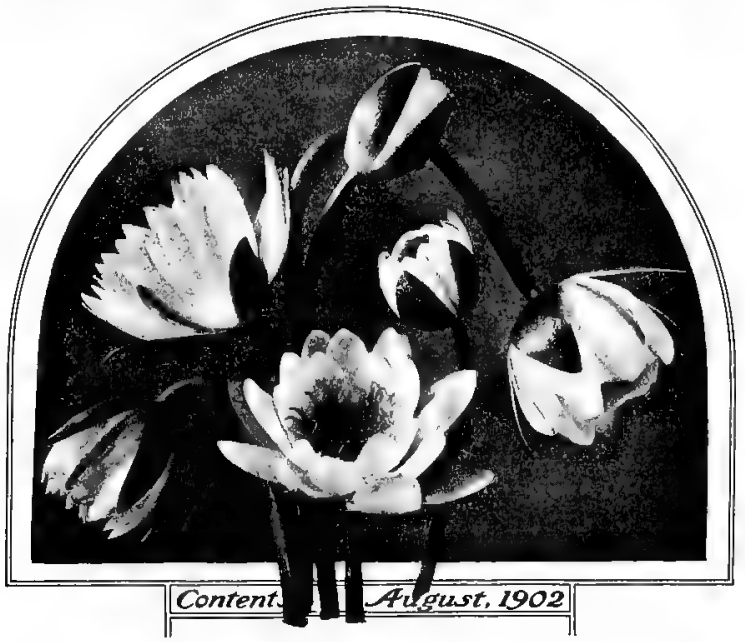

Water-lilies used to decorate a "Contents" page. This is applicable to many uses other than that here shown. See page 70 .

obviously rather small, and complexity means failure. The arrangement, also, should feel the influence of its purpose, in that the line should generally lead inward, toward the initial letter itself, and toward the printed page. I have seen some horrible examples in the way of initials in which a photograph had been used that necessitated the drawing in of the actual initial letter far from the upper right corner, and not close up to the word of which the first letter was purloined. The composition should always be so arranged as to permit 


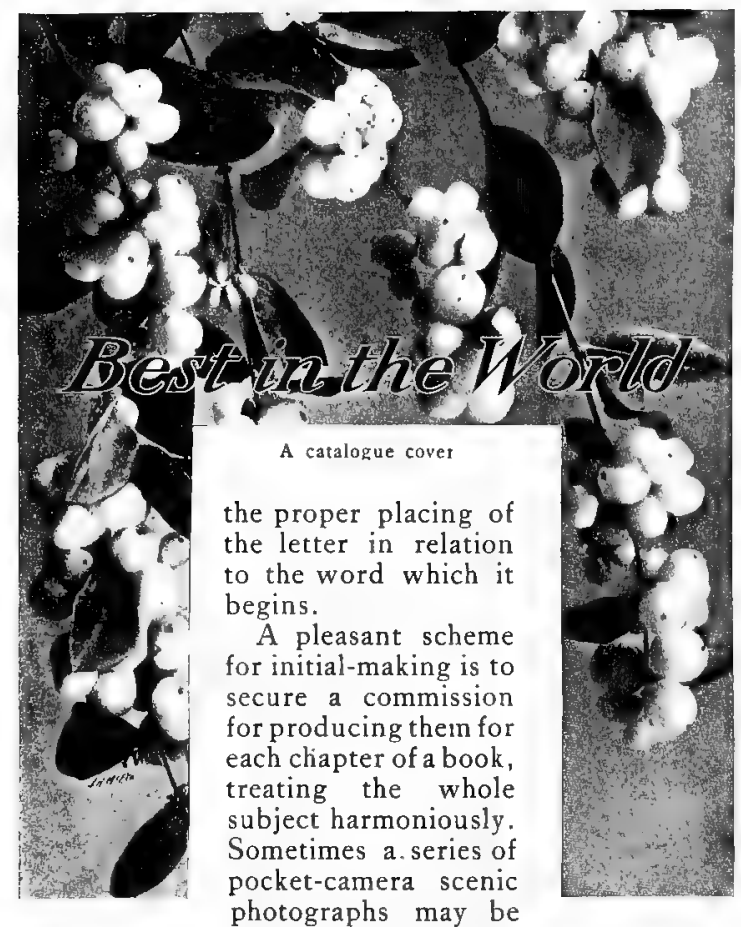

made to serve admirably for such use. Here again simplicity cannot too strongly be urged upon the photographer. The wide angle of the lenses usually fitted to the pocket-camera gives an opportunity to provide a central or striking object or figure as the motive, with the distance agreeably distorted by rapid reduction.

Catalogue and Booklet Covers

A wider market and an easier field in which to work decorative photography is in the designing of covers for catalogues and booklets, whose name is surely legion. When the sacred writer, in days of old, said that " of the making of books there is no end," he 
had no remotest conception of the publishing interests of this age, in which one firm, and that not notably the largest, issues two books each business day of the year. For each book, probably a thousand "booklets" appear, and the catalogue production is probably many times greater.

Not all booklets or all catalogues are potential subjects for the camera man with the designing eye, but I believe I am safe in saying that an increasing majority of them may be photographically decorated, given only the acute attention of the man who knows how. To illustrate, I cite the case of a successful nurseryman, the front of whose catalogue had remained "plain" for years, the cataloguer alleging that his customers preferred it so. One day, without discussion, I laid before him a photographic snowberry design that had been carefully worked out. His only words were: "I'll take it ; go ahead!'

The Design Here was the point - the purely Ready American point: When he saw the design, he wanted it at once; but if I had suggested the making of a design, he would not have been moved. We buy what we see, if we like it, and the acute merchant attracts by his accomplishments rather than by his promises. Therefore the photographer in this field must resolve to use his own brains in planning and making designs to offer, rather than to await commissions that will seldom come.

In designing covers for booklets or catalogues-and the line between the two is vague indeed-objects of any kind may be used photographically. While I might expect to attract the hatchet manufacturer by a suggestion of a cherry tree, it would have to be most obviously connected with the truth-telling desires of the father of our country to be more to the hatchet-man's fancy than a remarkably fine photograph of a young axe made by him. Machinery and tools, textiles, pottery of all sorts, shoes galore, corsets and lingerie-all these and countless other things have been and will be used decoratively and photographically in increasing measure as the workers rise to opportunity. The field is limitless, but not so easy that it is overcrowded, and the really good 
photographic cover design will always carry a good value to a ready market.

As the field is so wide, I can hardly

The Field attempt to more than hint at details and methods. My own practice has been rather large in extent, but limited in scope, and has dealt mostly with my favorite motives of trees, flowers, fruits and seeds. There is no reason whatever to feel, so far as I can determine, that the same methods will not bring success when applied in other lines and upon other objects. Indeed, since I have found the really exquisite beauty that resides in such prosaic subjects as beans and peas, I should feel an assurance of fair success in working out a design made with the free use of clothes-pins or with railroad spikes.

The frontispiece of this little book

Discussion of is a color-design of the blue fringed

Examples gentian, used upon the cover of a nurseryman's catalogue. The effect of the dainty flowers is given in three printings, but it was enhanced greatly by the decorative treatment. The flowers seem to be on a panel, raised up by the simple device of drawing shading lines on two edges, and this panel was mounted on a piece of rough drawing board, so that when the whole was photographically engraved the texture of the drawing board was shown on the otherwise glossy and smooth cover. Thus the objectionable gloss was simply removed, and the dainty elegance and beauty of the flower properly set off.

Decorative photography, by the way, Artists' Errors damages artists' conventions, at times. I have never been able to find any artists' holly to photograph, for instance; the real thing is very different, and is sometimes hardly recognized, although much more beautiful. Some years ago I wanted a design to include that most strikingly elegant and purely American plant, the common maize, or Indian corn. A very competent and usually successful designer brought me a sketch showing ears of corn growing from the ends of the great stalks, and, when I remonstrated with him, he declared that he could find no authoritative corn photograph or picture 


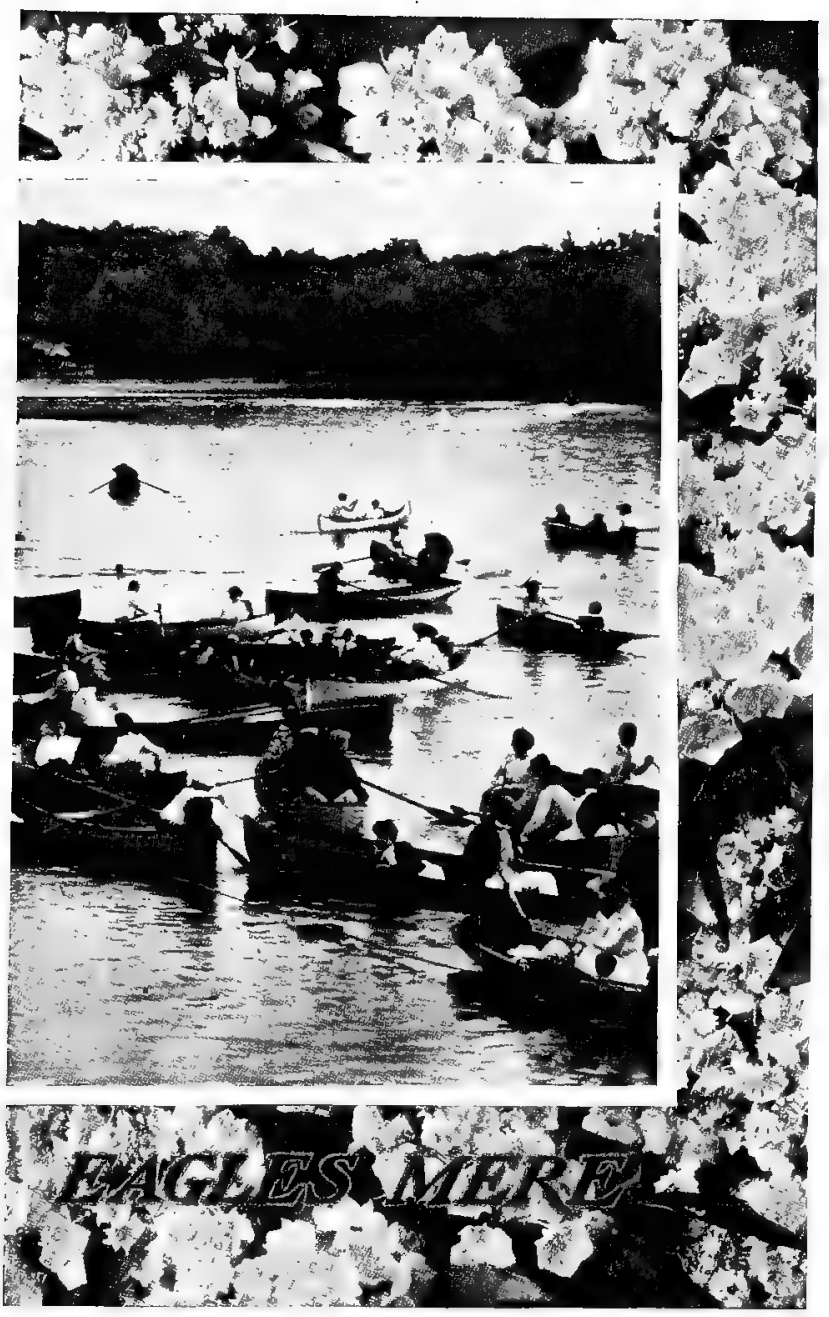

Flower detail may often be decoratively combined with an outdoor scenc for Resort" booklets. See page 76 . 
in any New York library! Since, I have taken pains to supply this need.

A Combi-

The Eagles Mere booklet cover shows nation a treatment including an available flower detail combined with a landscape view. The central photograph, which extended also on the back cover, was surrounded by the laurel flowers characteristic of the place, with good effect.

In another and utterly different case, the customer had a phrase in mind that served as a text for the cover designs for two successive years, reproduced on page 77. A patient succession of efforts was necessary to

"Faking"

Required get the right effect from the facial expression of the model, and an ingenious bit of "faking" was required to secure satisfactory results on the pile of vegetables in the corner of the 1904 cover, as well as on the basket crowning the boy's head for 1905 . The quick exposures necessary in each case to secure the momentary expression on the boy's face required a lens too far "wide open" to obtain depth of definition on the vegetables. Therefore these were separately photographed under the same conditions of light and to precisely the same proportions, the design artist working them together and adding the background.

Here may be mentioned a point in

Choice of design that ought always to be considBackgrounds ered. If these two schemes shown in the Holmes covers had been worked on wbite backgrounds-the plain paper color-they would have lost much of their effect. The gray or neutral background tends to direct attention strongly to the central idea and to the lettering of a real advertising feature of the design. It may almost be taken as a rule that if the area of white paper surrounding a design doubles the area of high-lights and middle tones within it, the effect will be dissipated; while if by a neutral background the highlights of the designs are emphasized, the eye will seek them naturally and the effect will be intensified. Calling to mind lantern-slides he has seen on the screen will enable any reader to test this dictum for himself, and I should be surprised to hear that any one considered a 


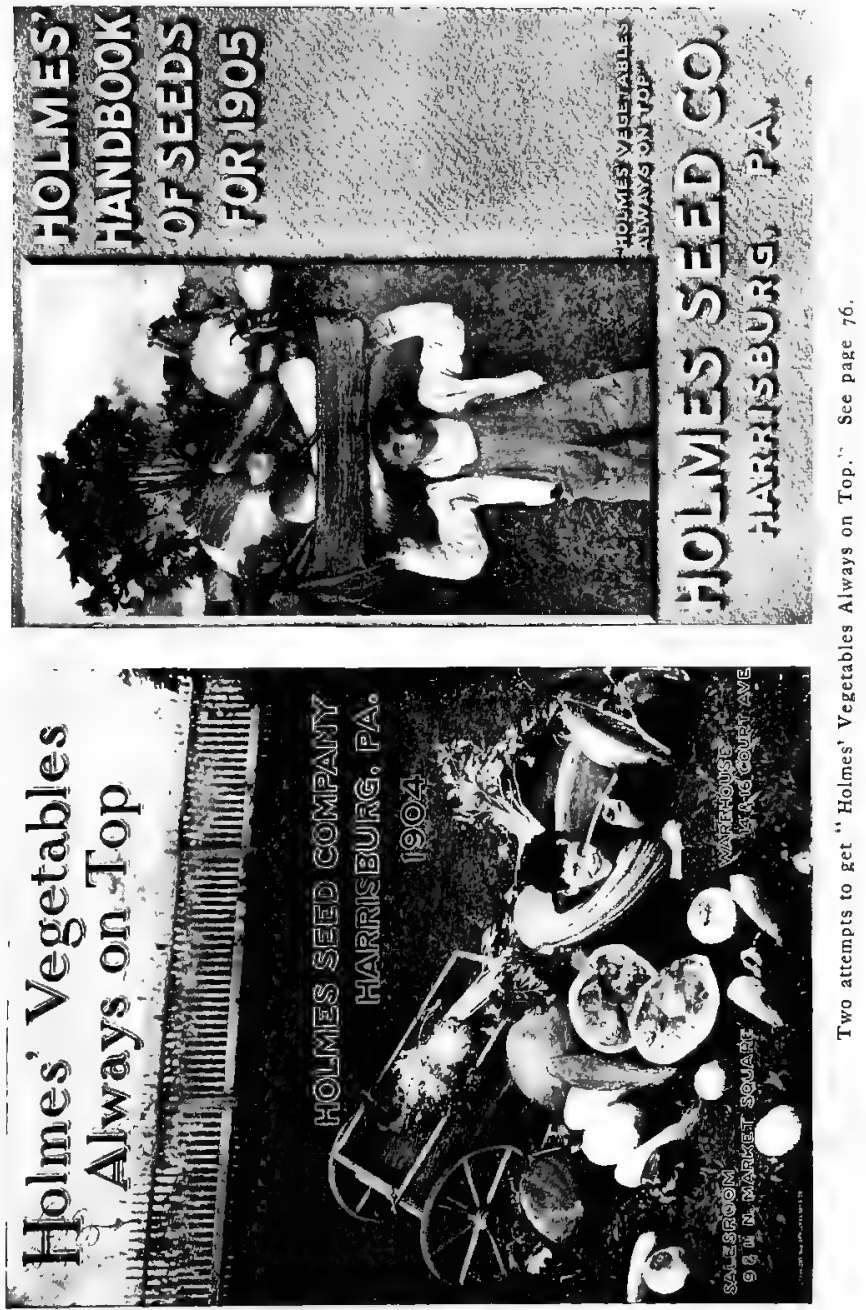


succession of white skies as agreeable, while all will remember the charm of views with clouded skies, or

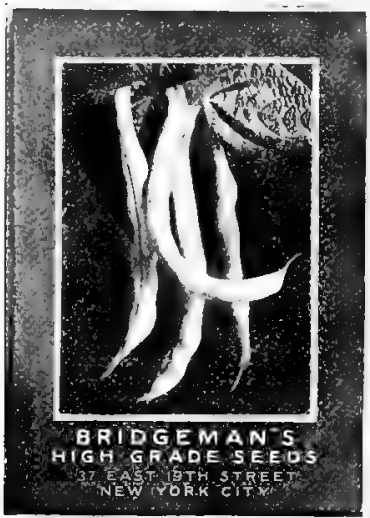
those in which the dark and middle tones of foliage serve to rest the eye and to direct attention to the main objects of the composition. The proportion and placing of the masses of white must be considered.

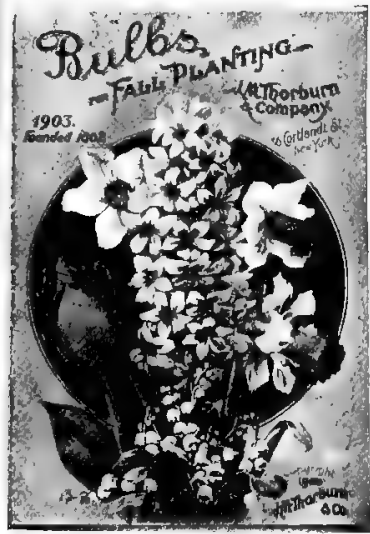

Three designs of catalogue covers. The two on the left are photographic designs from life, the right-hand cover being a lithographed design. Note the naturalness of the former compared with the latter.

On this page three cover designs A Comparison are shown in comparison. The two subjects to the left were photographically composed; the other was lithographic work. There 
can be no question as to the more agreeable character of the photographic designs, nor indeed as to their accuracy and naturalness. Particularly do I direct the attention of the student of design to the bean picture at the left, asking a consideration of the pleasing and attractive lines it presents.

This subject of the designing and photographic means of covers for catalogues and booklets might be exampled and extended to great length, but I think enough has been said and shown to set forth its pleasing possibilities to the earnest and ambitious student.

- Decorative A field for the photographic design Advertising worker that is almost limitless in its use and in the market for good designs is concerned with the making of schemes for magazine advertising. The pages of any of the leading magazines will prove this in the increasing use of photographs. For this work, almost any striking thing is useful, for the advertiser's first desire is to attract attention. Where the design is appropriate to the article to be advertised, it is all the better. For instance, I remember the pleasure an assistant of mine had several years ago in photographing his baby in the several stages of anticipation, demand, enjoyment and satiety as to a food preparation. His pleasure was not diminished by the satisfactory price paid him for the negatives by the manufacturers of the food.

The adaptability of flowers and the like to this phase of decorative photography is obvious, and much that has been said previously in this monograph will fully apply here. A point for consideration always is in connection with the proper location of the necessary wording. The composition should be so spaced that lettering may come in without destroying the design, and the worker must remember that the design is valuable only as it calls attention efficiently to the merits of the article advertised.

There is an increasing tendency

Use of the Model toward the use of figures in this sort of work, and that means more difficulty for the worker, as well as better compensation. The proper posing of models is an art by itself, and, while 
the subject is entirely germane to this discussion, I do not introduce it more than in the way of a passing mention, lacking that personal experience which is the basis of this monograph. I merely hint that patience and " a way with children" have been known to produce most pleasing results in designing for advertising.

For the home worker who wishes to

Christmas Cards make his holiday-giving distinct, and without flavor of the shops, and also for the ingenious designer who may want to work to a financial profit, the making of photographic Christmas cards will be interesting. Such cards are individual, and therefore far more pleasing to the recipient, usually, than the stock designs of the stores. A way to introduce a Christmas flavor into the productions, while also retaining the personal element, is to provide several negatives of holly, laurel, galax leaves, Christmas trees, ice-covered twigs, and other easily recognized holiday motives, arranging to mount these on the same card as the print from the purely individual negative. One able to draw letters successfully may also produce a Christmas wish in verse or prose, photographing it to any smaller size for use in connection with a picture bit that will be readily recognized by the recipient. A phrase of holiday cheer may be drawn upon a Christmas toy ball, with care, and keeping well inside onethird the circumference. This, photographed as hanging from a bough of a Christmas tree, with proper attention to lighting, will form a pleasing part of the card.

The Christmas dinner may have a photographic menu card, such as shown under a later heading on these pages. I remember one joyful occasion of this kind at which each guest found at his plate a red ribbon, which, when pulled at the arranged time, drew from the concealment of the center-piece a small photograph having a special appeal to him and bearing the felicitations of the day.

With just these hints, the home worker will see many ways in which the camera will provide charming adjuncts to the holiday giving, with a personal point that is always pleasing. Let me hint, however, that the best way to work is to provide the essential negatives a year 
in advance. Photograph the Christmas tree, or decorations, or the church adornment, or some occurrence of the day, sure that it will be valuable a year hence.

The same suggestions apply to Easter, Easter Cards now becoming almost as much a festival of joyous giving as is Christmas. The Easter opportunities are, however, decoratively much greater, as it is the custom to have many flowers in bloom at that time. Lilies are especially significant of the day, and all the spring-blooming bulbous flowers, as hyacinths, tulips, daffodils and the like, are in order for Easter remembrances. Of course one could not forget the lily-of-the-valley, most dainty and charming of spring blooms, and one, too, that will tax the decorative photographer's skill to the utmost, while as well rewarding him most richly for real success.

In obtaining negatives to use for making Easter cards care needs to be exercised, to work with the idea of simplicity of arrangement always in mind. I reiterate this, even though it become tiresome; for complexity has spoiled more floral compositions than any other fault. A single tulip, with its foliage; one rose and perhaps a bud; just two or three lily-of-the-valley blooms with their leaves-these, thoughtfully handled, will provide negatives of much value. The elusive beauty of the violet and the pansy may be put on glass, given enough plates and patience.

Birthday

Naturally, the use of photographically Cards decorated cards will appeal to the worker who must remember the natal days of his friends. A bit of a portrait, a scene in which the friend has had a part; a familiar flower, a nook in the home-suggestions will make themselves, almost, for anniversary use.

For all these uses, let me mention a plan that sometimes helps greatly in the finish of the result. Lettering is often essential to the card scheme, and many times the negative that seems appropriate is not the correct size. To mount the desired print on a proper card, to draw or write on it the words or phrases necessary, and then to carefully photograph the whole to the selected size is not very difficult. 
Selection

of Mounts

Just here there is opportunity for obtaining a pleasing result. The photograph may be mounted on a rough or pebbled cardboard, or on some form of bookbinder's cloth, or on one of the modern "art" mounting or cover papers, the texture of which will give a pleasing ground to the photograph. The words may be drawn directly on the mount, or on smooth or contrasting paper, and carefully put in place. A little shading with brush or pen will give a panel effect that is very attractive if properly done.

This plan is not available usually unless there is to be a considerable reduction in size, because of the difficulty of photographing a photographic print without losing much of the detail. If there is a fair reduction, and if the lighting of the scheme is so managed as to avoid exaggerating the grain of the photographic paper used for the original print, very good results may be had. The calendars and menu cards shown in these pages give proof on this point.

Obviously much that has been written

Making

Calendars

in the last few pages applies as well to the making of calendars by photography. There is no way in which the ingenious amateur may more agreeably and economically remember his friends at the holiday season than by a photographic calendar. I remember how at one New Year recurrence I helped greatly a public improvement by this means. It was desired, in my home city, to add to the park system a tract of native wild land, covered with trees and flowers, but practically unknown to most of the influential citizens of the town. It was winter, and a visit to the place was impracticable. I had a dozen or more good negatives, made in the natural park that it was hoped to have taken by the city, and I produced a score of calendars, choosing each photograph with special reference to its recipient. Neat little calendar pads were attached to the dark cards upon which the prints had been mounted, and a letter calling attention to the view accompanied each card as sent by messenger on New Year's Day. The effect was remarkable, for nearly every man responded with a personal note of thanks and apprecia- 
tion, and I saw the calendars hanging in the offices of these gentlemen all through the year then begun. The park proposition was helped, and it has since been successfully consummated.

For home friends the calendar is a pleasing way of reminding and of

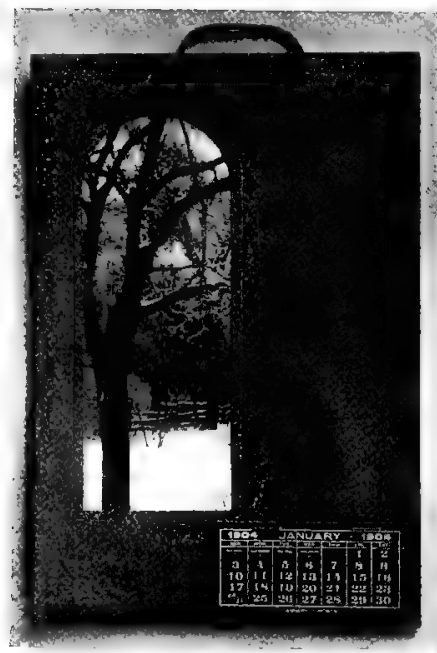

Suggestions for calerdars.

suitable narrow ribbon that serves as a hanger can be of a color that the sender knows will please the recipient. Two examples are reproduced herecomplimenting. The little pads to attach may be usually bought of the stationer or the printer, and the silk cord or

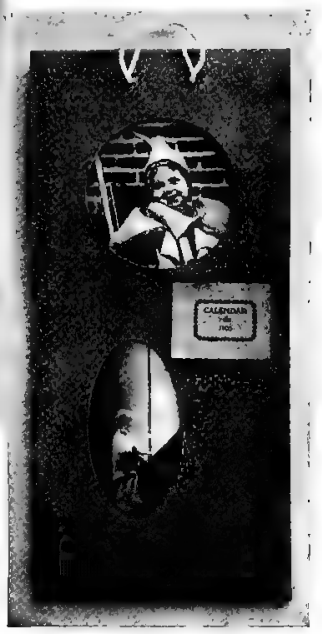

with, merely as suggestions. The round and oval shapes of the prints resulted from the use of brass forms, and on the calendar showing the snowy woodland the line around the picture was ruled with a blunt knife.

Calendars for Sale

There is another form of calendar making, however, that will provide a financial reward, if it be well managed. It is to make a local calendar, in three to twelve șheets, 
for sale in the home art- or book-stores. To produce this the decorative worker should begin a year ahead, to plan and obtain suitable seasonable negatives. He should decide as to his first attempt, whether to produce a calendar with three, four, six or twelve leaves. Then he may look out for subjects that suggest the months and possibly the local conditions. A familiar and attractive view, made with snow trimmings in winter, as the leaves break in spring, in full summer maturity, and with bare twigs for fall, is an example of the treatment. Or three, four or six views of characteristic scenes at various times; suitable flowersthese may be very closely associated with the monthsor fruits may be used to make a consistently attractive series. Pictures of a child in seasonable garb are always satisfactory if handled so as to get the unconscious charm of youth. A multiplicity of subjects will present themselves to the designing mind.

The adding of the calendar features

Calendar

"Pads" may be in several ways. The pads may always be had a year or more in advance, and six, four, three, two or one pasted directly on a card. By the use of the suggestion made for Easter cards, a pleasing and easily worked scheme may be arranged. To use out this idea, have the main design somewhat larger than it is intended to use it, and mount it on a card or paper of proportionate size, so that the whole may be carefully photographed together. Due caution must be exercised, in this copying method, to give full exposures, and to light so as to avoid the grain or gloss of the paper, as previously noted.

If the decorative worker is in anyway apt with crayon, brush or pencil, the months and dates can be drawn right on to the photograph, or the printed dates may be decorated or improved by careful handling. In the same way, a decorative treatment may be given to the selected photographs that will aid in an attractive or a profitable result.

"Half-tone"

If the design is to produce enough Calendars calendars to make a considerable sale, the making of photographic prints will be found onerous and expensive, and it will be imprac- 


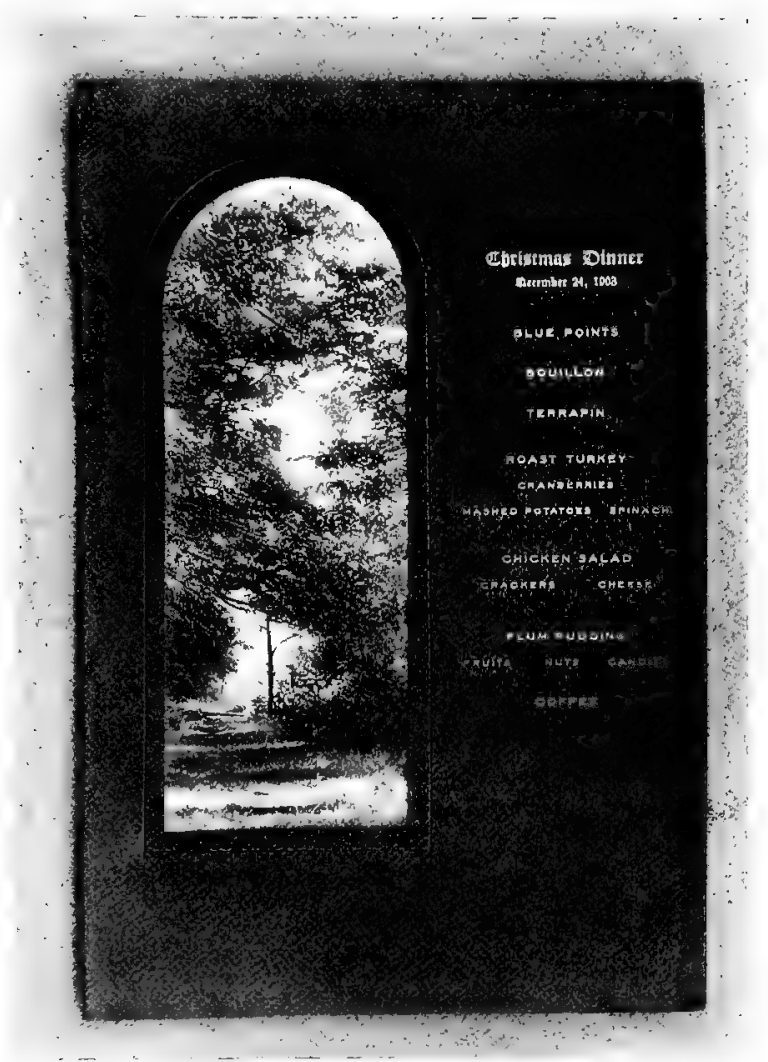

By varying the photograph, each guest may have a menu card embellished with a familiar scene. See page 87.

ticable to use any drawn or painted decorative addition. Here the modern perfected engraving processes come in ; for, by preparing one careful outfit as "copy," the production through the half-tone reproductive process of any number is rendered simple and cheap. It is not worth while or economical to undertake this for fifty or even a hundred sets of calendars, but for larger 


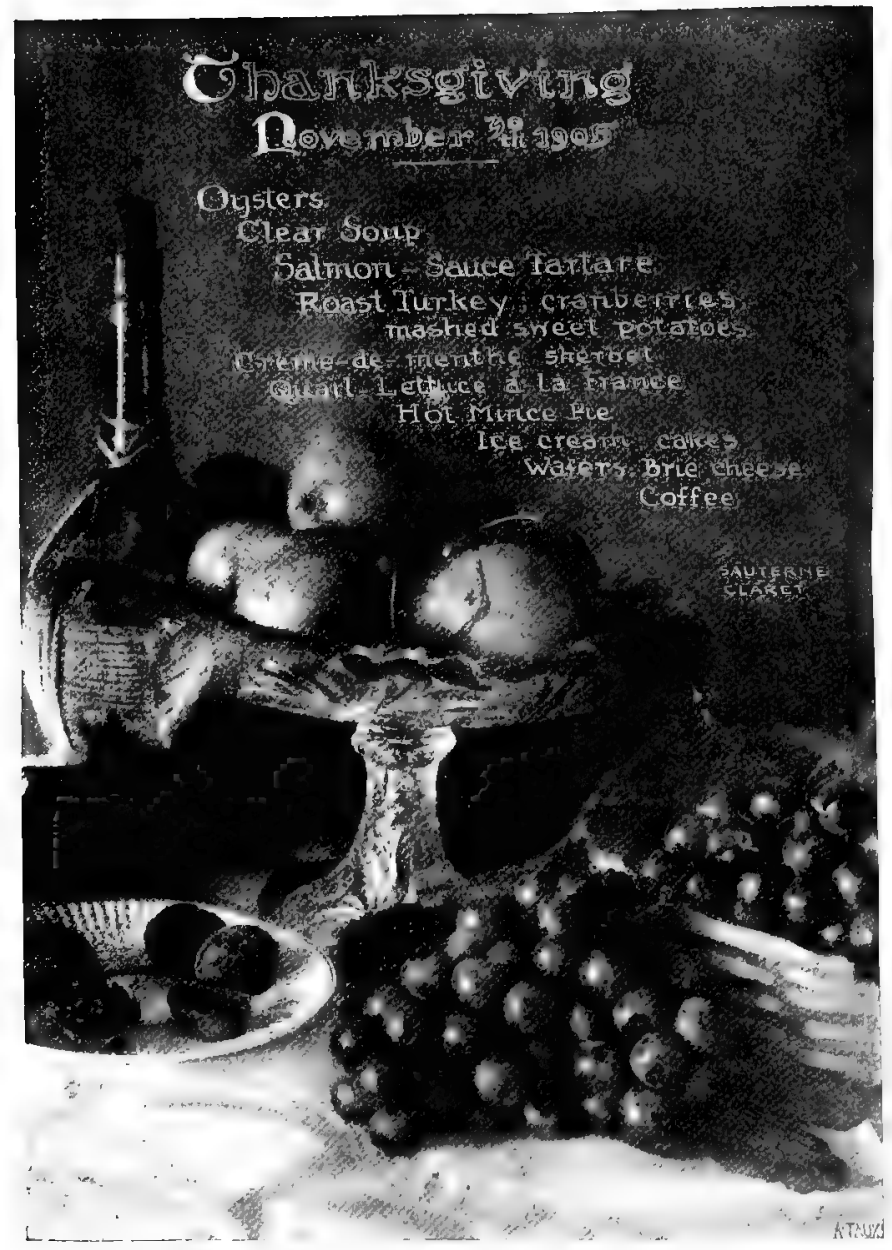

Hcre the menu was lettered on the photograph itself, which was then copied, From this negative menus were made on platinum parchment in sepia tone

A. Tauxe 
numbers it is entirely in line. To work with a capable engraver is necessary, as the cheap "square-inch" man, who makes a dab at a photograph and delivers the result as satisfactory, is sure to cause disappointment.

In proper hands, within two or three per cent of the beauty and gradations of a proper photographic or drawn "copy" can be held in the engraving, and the interested and skilled master-printer will put the same beauty on a thousand impressions.

Before leaving the smaller items, I

Menu Cards should mention the pleasing possibilities in the making of photographic menu cards, adapted to special occasions. In the Christmas dinner card shown on page 85 , various familiar scenes were selected, and each card was individualized for the guest. The menu was printed in white on a carbon black card, and the name of the guest also added. The effect was simple, elegant and satisfactory. It would not have been impracticable to have photographed the menu words, giving entire independence from the printer, for a home dinner.

In another case, this was done. The event was a dinner to city officials, given by the mayor of the city. At the top and the bottom of the card were mounted selected views of the city, and between, the menu carefully drawn, with a blank for the name of the guest. The whole was photographed down to convenient size, and the negative printed very carefully on portrait Velox, keeping absolutely clear whites. When mounted on a carbon black folder, the effect was very satisfactory, as well as unique.

General

Schemes

Enough has been written in these pages to offer ample suggestions to the interested and acute worker for many effects not even hinted at. The camera will prove, in facile hands, a decorative agent of breadth, profit and power, especially for these smaller items.

Keeping entirely clear of the use of

Photographíc

Room

Decorations

framed pictures of various kinds, there is yet unconsidered a most striking opportunity to use photographic decorations in the rooms of the home or the shop. In these days 
the tendency seems to be toward a recurrence of strongly figured wall coverings. I remember the joy with which a talented and tasteful woman told me that she had unearthed twenty or thirty rolls of wall-paper, made some fifty years ago in a strongly decorative way, showing not a small, constantly repeated figure, but a broad, sketchy design, with which she wished to adorn her new dining-room in the vogue of the present.

\section{An Onion Motive}

The plan I am about to suggest affords opportunity to exercise the talent, taste, skill and fancy of the home-maker upon the walls, and the result need not be of a character to cause one to see flaming grapes in a nightmare, or to have a Japanese delirium. The idea is simply to select some object that has decorative possibilities, to photograph it with due consideration of its lines, and to make enough prints to serve as a border next a wainscoting, or as a frieze above the picture railing, or, indeed, below, if the general plan of the room will so permit. Curiously enough, the photograph which gave form to this idea was of an object not usually considered decorative in any sense, or, indeed, in any way beautiful-namely, the odorous spring onion! Two of these silvery skinned vegetables, with their green tops, had been photographed in a pleasing composition, and several prints, lying close together, produced promptly the thought of a repetition which would be decorative. Since then, after much study and experiment, the plan has been tried with entire success and satisfaction, and it is confidently recommended as a way in which the home rooms may reflect, not the ideas of some decorative wallpaper artist on the other side of the world, but the best thought of the people in the home.

\section{Placing of Lines}

In planning for this sort of a decoration, one must avoid the pitfall of a bad placing of mass or lines. For instance, as $I$ write $\mathrm{I}$ an looking at three unsuccessful examples which promised absolute success when they were planned. One is a cluster of two peaches with their leaves-a beautiful negative and a charming picture. Repeated, however, the peaches tend to carry the line across the room instead of up and down, and they give 
a spotty effect that is not pleasing. Again, I look at a very beautiful orange with its foliage, also apparently decorative, because the direction of the line is beyond criticism. Bùt here, again, the mass of high lights makes the use of it for the decorative frieze that was planned entirely unsatisfactory.

The onions above mentioned are entirely successful. A bunch of cucumbers bade fair to do perfectly well; but here a false direction of line, leading the eye outward and away, has made the little section of frieze in my experimental room anything but pleasing. Next to it is a joy, a section devoted to a bunch of celery, which has been repeated so that it gives a smooth, clean and altogether pleasing effect, beyond criticism as to mass color and line, and ideally satisfactory for a dining-room decoration.

It will be observed here that I have Vegetables in spoken familiarly of vegetables as deco-
Decoration rative, and I do so purposely and advisedly. Some years ago my work made it necessary for me to undertake the photographing of vegetables in full size with the vertical camera-stand described in the preceding monograph, page 25 . I will confess that I undertook the work with some displeasure, because it seemed to me that I could find more pleasing objects to work with, if I were given any choice, than the prosaic vegetables of the markets. No sooner, however, had I undertaken to make composition of peas and beans, the first objects it was necessary to handle, than I discovered the most attractive possibilities. Delightful arrangements of lines proved to be practicable, and there was enough difficulty in the composition, in the lighting, and in the proper exposure, to make the satisfactory results that finally came all the more pleasant to consider.

In this experimental room I look also at a section devoted to a bunch of white grapes photographed on a dark background, almost full size, and entirely in the proper key in every respect. While the grapes carry high lights, these lights are so distributed in the bunch as to avoid the spottiness that spoiled the oranges and peaches before mentioned. 
Presented with this are little sections of a frieze, to show the effect of the grape massing, and another of a composition of daffodils, the latter of an entirely successful character. I have in use other motives, including roses, carnations and other suitable flowers, and I have selected from among my negatives an iris subject that promises well.

I believe the pictures shown herewith and the hint given in the paragraphs that precede explain the idea of this individual decorative plan for the living-rooms. It is hardly necessary to say in extension that the thoughtful worker who is after pleasant effects in his own home will have no difficulty in making his selections for the various rooms. He will turn at once to vegetables or fruits for the dining-room, perhaps, unless he is a fisherman, to give him a chance at real trout. He will want flowers for some of the other rooms, and his own imagination or taste will doubtless lead to the use of motives of which I have not even dreamed. I can therefore drop the consideration of the idea and give a little

Doing the Work attention to the method of doing the work, which will avoid for the interested decorative worker who attempts this scheme, now, I believe, for the first time mentioned, some of the pitfalls I have had to climb out of. It will be obvious that small prints will not be satisfactory for this decorative idea. The whole-plate size, $61 / 2 \times 81 / 2$, or better yet, $8 \times$ Io, will give enough of flexibility to render the work possible. Or even better yet, a IO $x 12$ negative, if the worker's pocketbook will stand the expense of the many prints, will aid in producing, under the handling of good taste, a superb result. It needs to be said, though almost obvious, that but one motive can be successfully used in a room, in accord with all the principles of decorative art. I may as well confess that I did not believe this, and I therefore used in my experimental room eleven motives in as many panels, proving fully that but one was desirable.

An Even In photographing, an attempt must be Background made to get an absolutely even tinting of the background, so that when the prints are repeated there is no disagreeable break in 
tone. Some very pleasing negatives have had to be rejected because of failure in this respect. I do not by this mean to indicate that white backgrounds are necessary, or even desirable; for so far as I have pur-

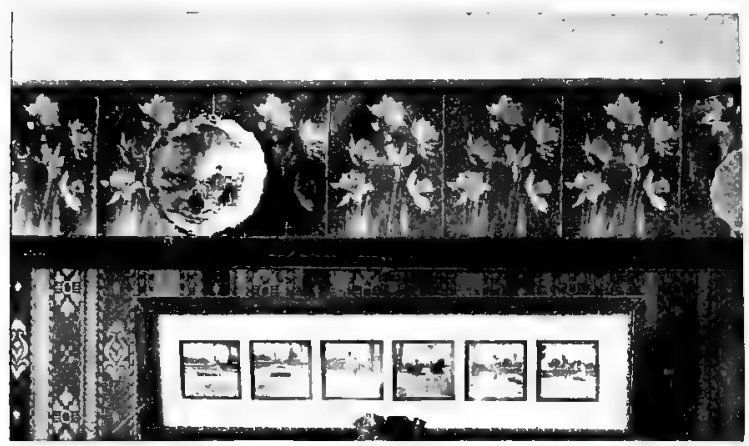

Section of friezes suggesting the use of photographs of flowers and fruits in life size. See page 87 , et seq.

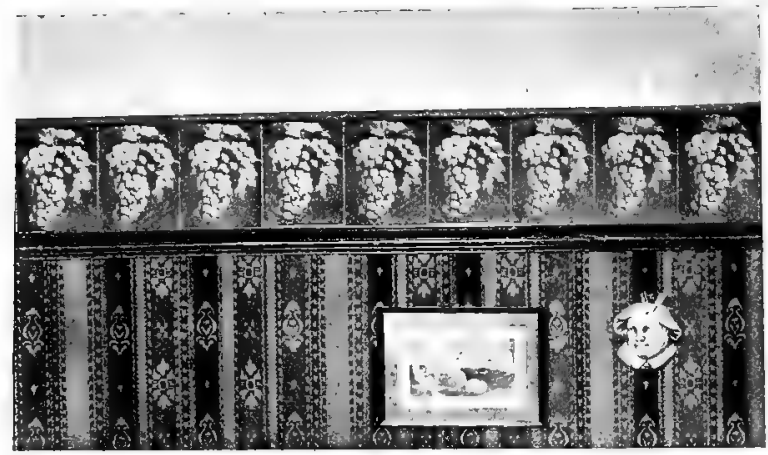

sued this subject they are seldom available, detracting too much from the detail of the motive unless it is extremely light and airy in outline. A medium background, such as could properly be called neutral, and 
such as is usually afforded by a dark gray cardboard below the glass exposing-stage of the vertical camerastand, gives the best average results. Here again the interested worker will experiment for himself, and he may easily prove me to be entirely wrong in this matter of the tint of backgrounds.

\section{Uniform \\ Prints}

Next I need to mention that to secure the uniformity desirable the prints must all be alike in tone. For a room of comparatively small size forty or fifty prints will be needed, and they should be absolutely uniform, if that is possible; but if it is not possible, they should be as nearly uniform as they can be made, and should then be selected, so that the differences are imperceptible when they are placed one next to another.

I find that with the very best of care in this respect there will be differences, and I have evolved a plan for helping out these differences. It consists of pasting a thin strip of paper of a color harmonious with that of the background, but a little lighter or a little darker, between the photographs as they are mounted for suspension on the wall. This strip of paper should not be over one-eighth of an inch wide, usually. It will panel the motive and cover the joints.

By far the easiest way to handle this scheme is to paste the photographs on linen mounting cloth. They are then in flexible shape, and can be managed readily.

The Tone of

The tone of the photograph is of the Prints very great importance, and depends, of course, on the color of the room which is to be decorated. The experimental room in which I sit has walls of green burlap, with a dark brown stained wainscoting. The black-and-white tones of Portrait Velox were cold and unsatisfactory, but the brown tones of Eastman Sepia, or the richer browns of the re-developed Velox, are just right. The carbon printer, who has at his command a great range of colors and tones, will find no difficulty in fitting any color scheme. Parenthetically, well-made blue-prints of uniform tone will be found exceedingly dainty and pleasant in a room with light walls, that will stand the juxtaposition of masses of rich blue. 
No Glass

Covering

When this photographic frieze is finished, it needs to be considered as a part of the wall scheme, and not as a picture hung out of sight. It cannot be covered with glass, therefore, as the reflection from the glass will spoil the general effect, which should be soft. If the prints are carefully made, fully fixed, and well washed and toned, so that they are permanent, there should be no difficulty about durability. A mat varnish would assure permanence. Where the frieze has been hung under a picture-rail I have bound it by a small round molding, completing the frieze idea; and in the same way a treatment above the picture-rail seems to be obviously incomplete without some slight binding.

I am of opinion that there is a fascinating possibility for home decoration in this photographic frieze scheme, and I believe as fully that it can be worked out by some photographer with taste and ability into a profitable means of providing unique and individual decorations for people of wealth and taste, who have not the skill, time or inclination to do such things for themselves, but are willing to part with the coin of the realm to the artistic decorator who can give them something that no one else has, probably, from motives obtained on the place and absolutely suiting the environment.

To plan photographic motives for decorating pottery ; to furnish patterns for fine linens; to get rid of the artistic abominations and conventionalizations that make some woven fabrics anything but beautiful, when they might be beautiful; to plan motives for wall-papers that will be the real thing; these and scores of other possibilities are ahead of the decorative photographic worker, who takes up, with courage, skill and taste, a line of work that is as yet practically untouched, or at least undeveloped.

\section{J. Horace McFarland.}

Note. All the examples in the foregoing pages are from Mr. McFarland save those otherwise noted. 








